\title{
Binocular Input Coincidence Mediates Critical Period Plasticity in the Mouse Primary Visual Cortex
}

\author{
Xiao-jing Chen, ${ }^{1}$ Malte J. Rasch, ${ }^{2,3}$ Guang Chen, ${ }^{1}$ Chang-quan Ye, ${ }^{1}$ Si Wu, ${ }^{2,3}$ and Xiao-hui Zhang ${ }^{1,2}$ \\ ${ }^{1}$ Institute of Neuroscience and State Key Laboratory of Neuroscience, Shanghai Institutes for Biological Sciences, Chinese Academy of Sciences, and \\ University of Chinese Academy of Sciences, Shanghai 200031, China, ${ }^{2}$ State Key Laboratory of Cognitive Neuroscience and Learning \& IDG/McGovern \\ Institute for Brain Research, Beijing Normal University, Beijing 100875, China, and ${ }^{3}$ Center for Collaboration and Innovation in Brain and Learning \\ Sciences, Beijing Normal University, Beijing 100875, China
}

Classical studies on the development of ocular dominance (OD) organization in primary visual cortex (V1) have revealed a postnatal critical period (CP), during which visual inputs between the two eyes are most effective in shaping cortical circuits through synaptic competition. A brief closure of one eye during CP caused a pronounced shift of response preference of V1 neurons toward the open eye, a form of $\mathrm{CP}$ plasticity in the developing V1. However, it remains unclear what particular property of binocular inputs during CP is responsible for mediating this experience-dependent OD plasticity. Using whole-cell recording in mouse V1, we found that visually driven synaptic inputs from the two eyes to binocular cells in layers $2 / 3$ and 4 became highly coincident during CP. Enhancing cortical GABAergic transmission activity by brain infusion with diazepam not only caused a precocious onset of the high coincidence of binocular inputs and OD plasticity in pre-CP mice, but rescued both of them in dark-reared mice, suggesting a tight link between coincident binocular inputs and CP plasticity. In Thy1-ChR2 mice, chronic disruption of this binocular input coincidence during CP by asynchronous optogenetic activation of retinal ganglion cells abolished the OD plasticity. Computational simulation using a feed-forward network model further suggests that the coincident inputs could mediate this CP plasticity through a homeostatic synaptic learning mechanism with synaptic competition. These results suggest that the high-level correlation of binocular inputs is a hallmark of the CP of developing V1 and serves as neural substrate for the induction of OD plasticity.

Key words: BCM theory; cortical inhibition; critical period; input coincidence; mouse primary visual cortex; ocular dominance plasticity

\section{Introduction}

Postnatal critical period (CP) is a defined time window during which neuronal connections in the brain are malleable to sensory experiences. This is best exemplified by visual input-dependent ocular dominance (OD) plasticity of developing primary visual cortex (V1) in mammals, such as monkey (Hubel et al., 1977; LeVay et al., 1980), cat (Wiesel and Hubel, 1963; Hubel and Wiesel, 1970; Shatz and Stryker, 1978), ferret (Issa et al., 1999), and rodents (Dräger, 1978; Maffei et al., 1992; Gordon and Stryker, 1996; Frenkel and Bear, 2004), whereby 3-4 d of closure of one eye [monocular deprivation (MD)] during the CP causes a dramatic shift of the eye input preference of V1 neurons toward the nondeprived eye. Further studies with binocular occlusion (Wiesel and Hubel, 1965; Ohzawa and Freeman, 1988), alternating monocular occlusion (Hubel and Wiesel, 1965), artificial strabis-

Received June 21, 2013; revised Dec. 16, 2013; accepted Jan. 6, 2014.

Author contributions: X.-j.C., M.J.R., S.W., and X.-h.Z. designed research; X.-j.C., M.J.R., C.-q.Y., and X.-h.Z. performed research; X.-j.C., M.J.R., G.C., S.W., and X.-h.Z. analyzed data; X.-j.C., M.J.R., and X.-h.Z. wrote the paper.

This work was supported by grants from the State Key Research Program of China (Grant 2011CBA00403 to X.-h.Z.) and the National Science Foundation Program (Grant 31371109 to M.J.R.). X.-h.Z. acknowledges the support of the Sanofi-Aventis Shanghai Institutes for Biological Sciences Scholarship Program. We thank Dr. M.-m. Poo for his comments on this work and Dr. G.-p. Feng for providing the Thy1-ChR2 mice.

Correspondence should be addressed to Xiao-hui Zhang, State Key Laboratory of Cognitive Neuroscience, Beijing Normal University, Beijing 100875, China. E-mail: xhzhang@bnu.edu.cn.

DOI:10.1523/JNEUROSCI.2640-13.2014

Copyright $\odot 2014$ the authors $\quad 0270-6474 / 14 / 332940-16 \$ 15.00 / 0$ mus (Hubel and Wiesel, 1965; Maffei and Bisti, 1976; Smith et al., 1979), or stroboscopic rearing (Kennedy and Orban, 1983) in animals during the $\mathrm{CP}$ have demonstrated that correlated visual inputs between the two eyes are required for the competition between the afferents from the two eyes to their common cortical target cells. Moreover, theoretical and modeling studies have suggested that aspects of such experience-dependent synaptic competition between inputs from the two eyes to the developing V1 can be understood by considering synaptic learning rules, such as correlation-based Hebbian modifications (Stent, 1973; Miller et al., 1989), spike rate-dependent Bienenstock-Cooper-Munro (BCM) rule (Bienenstock et al., 1982; Cooper and Bear, 2012), or spike timing-dependent synaptic plasticity (Song et al., 2000; Song and Abbott, 2001). All these previous studies have pointed to great importance of correlated binocular inputs in the development of OD organization in V1 during the CP. However, it remains unclear what specific change in the property of binocular inputs to V1 cells emerges during the CP that makes this period particularly sensitive to the correlation in binocular visual inputs.

Accumulating genetic and cellular evidence from the mouse studies has revealed that cortical inhibitory activity mediated by GABA transmission is a key factor that regulates the onset timing of CP (Hensch, 2005; Espinosa and Stryker, 2012). It has been hypothesized that inhibition gates OD plasticity by regulating the correlation between binocular inputs in V1 (Feldman, 2000; 
Hensch, 2005). This hypothesis still lacks experimental support. In the present study, by performing in vivo whole-cell recording in developing mouse V1, we directly demonstrated that visually driven synaptic inputs originating from the two eyes to V1 binocular cells in the layer $2 / 3$ and 4 became more coincident during the $\mathrm{CP}$, a developmental process that depended on GABAergic inhibitory activity. Chronically disrupting the binocular input coincidence during the $\mathrm{CP}$, through asynchronous optogenetic activation of retinal ganglion cells in transgenic Thy1-ChR2 mice, abolished OD plasticity. Computational simulation using a feedforward network model subjected to a type of homeostatic synaptic weight learning adaption (BCM rule) further suggests that coincident binocular synaptic inputs during the CP mediates experience-dependent OD plasticity of developing V1.

\section{Materials and Methods}

Animal preparation. All surgical and experimental procedures were performed with the approval of the Animal Care and Use Committee of the Institute of Neuroscience, Chinese Academy of Sciences (reference number: NA-100418). Wild-type C57BL/6 (male only) and heterozygous Thy1-ChR2-EYFP transgenic mice (kindly provided by Dr. G.-p. Feng at the Massachusetts Institute of Technology) at postnatal days (P) 17-19, P27-P29, or $\sim$ P60 were used. Mice were normally reared on a 12/12 h light/dark cycle, while dark-reared (DR) mice were kept in the dark environment from birth. In the experiments of MD, eyelid suture was made to one eye in the mouse under isoflurane anesthesia ( $1-3 \%$ in oxygen), as described previously (Gordon and Stryker, 1996). After the recovery from the anesthesia, the mice were exposed to normal 12/12 h light/dark rhythm, and the eyelid suture was kept for $4 \mathrm{~d}$. The mice were daily checked to ensure the sutured eye remained closed and uninfected.

The surgery and electrophysiological recording were made in mice that were anesthetized by intraperitoneal injection of ketamine $(50 \mu \mathrm{g} / \mathrm{g}$ weight $) /$ medetomidine $(0.6 \mu \mathrm{g} / \mathrm{g})$ and mounted on a custom-built mouse stereotaxic device in most experiments. The animal heart rate and body temperature were monitored for the state of anesthesia, and additional one-third of the initial dose was given to sustain stable anesthesia if necessary. Body temperature was maintained at $37^{\circ} \mathrm{C}$ by a homeostatically controlled heating pad (RWD Life Science). For the recording, a craniotomy was made over the binocular zone ( $\sim 3 \mathrm{~mm}$ lateral lambda) of mouse V1 (Dräger, 1975; Gordon and Stryker, 1996) and the dura mater was carefully removed. Warm saline was frequently applied onto the exposed cortical surface, and eye drops were applied when necessary to prevent the eyes from drying. When testing for effects of anesthesia, a mixture of pentobarbital ( $50 \mu \mathrm{g} / \mathrm{g}$ body weight) and sedative chlorprothixene $(0.2 \mathrm{mg})$ was used instead.

Chronic light conditioning in Thy1-ChR2 mice. Both male and female Thy1-ChR2 transgenic mice were used for the light conditioning. Two customized shell-shaped goggles, each of which held a small blue LED (wavelength, 467-470 $\mathrm{nm}$ ) to stimulate the two eyes separately, were installed to the Thy1-ChR2 mice at P21 under anesthesia with isoflurane (1-3\% oxygen) by gluing around the eyes. Mice wearing the goggles could normally open and close their eyelids and freely move in the cage. The intensity of blue LED light ( $5 \mathrm{~V}$ DC power supply) was $\sim 0.4 \mathrm{~mW} /$ $\mathrm{mm}^{2}$ at the position close to the eyes, which could effectively evoke the synaptic activities in the V1 (see Fig. 7). The blue-light stimuli to the eyes consisted of trains of five light pulses $(5 \mathrm{~ms})$ at $2.5 \mathrm{~Hz}$, with intertrain intervals of $5 \mathrm{~s}$. For the asynchronous pattern applied to the two eyes, the light stimuli to the contralateral eyes preceded those to the ipsilateral eye by $50 \mathrm{~ms}$, while for the synchronous pattern, LEDs of the contralateral and ipsilateral eyes were activated simultaneously. The timing and duration of the LED light stimuli were controlled by a Master-8 (A.M.P.I.). The transgenic mice were conditioned with these patterned blue-light stimuli for $12 \mathrm{~h}$ per day from P22 to P25.

Drug infusion. The procedure of daily infusion of diazepam (DZ) to the mouse brain followed a method described previously (Fagiolini and Hensch, 2000; Iwai et al., 2003) with some modifications. Mice were anesthetized with isoflurane (1-3\% in oxygen) and stereotaxically in- jected with $1.5-2 \mu \mathrm{l}$ of DZ ( $2 \mathrm{mg} / \mathrm{ml}$ in a vehicle solution containing $50 \%$ propylene glycol, $49 \% \mathrm{H}_{2} \mathrm{O}$, and $1 \% \mathrm{DMSO}$ ) into the lateral ventricles of both hemispheres (coordinates from bregma: anteroposterior, -0.3 $\mathrm{mm}$; mediolateral, $1 \mathrm{~mm}$; dorsoventral, $2-2.5 \mathrm{~mm}$ ), and each side injection was completed within $10 \mathrm{~min}$. Injection of the drug or vehicle solution was made consecutively for 3-5 d. For mice reared in darkness, the injection was performed under red-lamp lighting. The stereotaxic position of the lateral ventricles for the drug injection was confirmed with fluorescence dye (Alexa Fluor 488, $10 \mathrm{kDa}$ dextran conjugate; Invitrogen).

Visual stimulation. Visual stimuli were generated by our customdeveloped software using LabView (National Instruments) and MatLab (Mathworks), and were presented on a 20 inch cathode ray tube (CRT) monitor (Sony Multiscan G520; $40.5 \times 30.5 \mathrm{~cm}$; refresh rate, $60 \mathrm{~Hz}$; maximum luminance, $80 \mathrm{~cd} / \mathrm{m}^{2}$ ). The CRT monitor was placed $20 \mathrm{~cm}$ away in front of the mouse, subtending about $105 \times 80^{\circ}$ of the visual field. Two customized electromechanical shutters were put close to individual eyes and alternately opened by electric pulses to achieve monocular visual stimulation.

All experimental sessions began with full-screen drifting sinusoidal gratings of varying orientations (spatial frequency, $0.02 \mathrm{~Hz} /$ degree; temporal frequency, $2 \mathrm{~Hz}$ ) to determine the preferred orientation of the recorded V1 cells. In the experiments examining the latency of evoked postsynaptic potentials (PSPs) and binocular integration, full-screen static gratings with defined optimal orientation (spatial frequency, 0.013 $\mathrm{Hz} /$ degree) of varying spatial phases $\left(0,120\right.$, or $240^{\circ}$, in a pseudorandom sequence) were then presented for $0.3 \mathrm{~s}$. The intervals between static gratings varied in the range of $0.9-1.3 \mathrm{~s}$. In experiments quantifying the ocular dominance with extracellular single-unit recordings, full-screen drifting gratings with optimal orientation were used. Each trial consisted of $2 \mathrm{~s}$ of drifting gratings and 3-4s of blank frames. We followed a method of a previous study (DeAngelis et al., 1993) to map the spatiotemporal receptive fields (STRFs) of recorded V1 cells on the basis of the evoked subthreshold PSPs. The bright squares in an $8 \times 8$ grid (pixel size, $9-11^{\circ}$ ) were generated in a pseudorandom sequence at a frame rate of 12 , 15 , or $20 \mathrm{~Hz}$. Each position had 50 or 100 repetitions. In the experiments testing the dependence of the ipsi-contra latency difference on the stimulus luminance, three different levels of mean luminance of static gratings $\left[40 \mathrm{~cd} / \mathrm{m}^{2}(100 \%), 20 \mathrm{~cd} / \mathrm{m}^{2}(50 \%)\right.$, and $\left.10 \mathrm{~cd} / \mathrm{m}^{2}(25 \%)\right]$ were used, while the stimulus contrast was kept unchanged.

Electrophysiology. Whole-cell recordings were made on cortical cells located in the binocular zone of mouse V1 (2.8-3.2 mm lateral from the lambda; Dräger, 1975; Gordon and Stryker, 1996), under the mode of current clamp with an Axon MultiClamp 700B amplifier (Molecular Devices), as described previously (Ye et al., 2010). The borosilicate glass micropipettes (Sutter) were pulled with a P-97 micropipette puller (Sutter), with a tip opening of $\sim 2 \mu \mathrm{m}$ and the resistances ranging from 8 to 12 $\mathrm{M} \Omega$ when filled with the internal solution containing (in $\mathrm{mm}$ ) the following: $140 \mathrm{~K}$-gluconate, $2 \mathrm{MgCl}_{2}, 10 \mathrm{HEPES}, 0.05 \mathrm{CaCl}_{2}$, 0.4 EGTA, 4 Mg-ATP, $0.4 \mathrm{Na}_{2} \mathrm{GTP}$, and $10 \mathrm{Na}_{2}$ phosphocreatine, $\mathrm{pH} 7.20(\sim 290$ mOsm). For the neuronal morphology reconstruction of a subset of recorded cells, biocytin $(0.4 \%)$ was included in the internal solution. Extracellular single-unit data shown in Figures 5, 6, and 9 were recorded with glass micropipettes in the binocular zone of mouse V1, with 3-4 penetrations spanning across the mediolateral extension of binocular zone, to quantify the OD distribution of visual cortical cells, following the previous method by Gordon and Stryker (1996). The extracellular recording micropipette was filled with the artificial CSF consisting (in $\mathrm{mM}$ ) of the following: $124 \mathrm{NaCl}, 2.5 \mathrm{KCl}, 2 \mathrm{MgCl}_{2}, 2 \mathrm{CaCl}_{2}, 1.25 \mathrm{NaH}_{2} \mathrm{PO}_{4}, 26$ $\mathrm{NaHCO}_{3}$, and 11 D-glucose, $\mathrm{pH} 7.35(\sim 303 \mathrm{mOsm})$, with the resistance of 5-7 M $\Omega$. Electric signals were filtered at $5 \mathrm{kHz}$ (low pass), digitalized by a Digidata 1440 A converter board (Molecular Devices) and acquired at $10 \mathrm{kHz}$ with the pClamp10 (Molecular Devices) into a computer for further analysis. The extracellular spike data shown in Figures 7 and 8 were recorded with single tungsten microelectrode $(0.8-1.0 \mathrm{M} \Omega$; FHC) or 16-channel multielectrodes (NeuroNexus Technologies). The neural signals of spikes were amplified and filtered with a Cerebus 32-channel system (BlackRock Microsystems). Single units were sorted based on 
Klustakwik clustering analysis of waveforms (Harris et al., 2001) using a custom-written software for supervision.

Immunohistochemistry and fluorescence imaging. To identify the neuronal loci of expression of channelrhodopsin-2 enhanced yellow fluorescent protein (ChR2-EYFP) in the retinal tissue, the retinas from heterozygous Thy1-ChR2-EYFP mice were dissected, sectioned, and imaged, following a method described previously (Thyagarajan et al., 2010). Briefly, each dissected retina was fixed in $4 \%$ paraformaldehyde in PBS for $30 \mathrm{~min}$, and dehydrated in graded sucrose solutions (10, 20, and 30\% in PBS). Vertical cryostat section ( $14 \mu \mathrm{m}$ thickness) or a whole retina was mounted on the glass slide for acquiring EYFP fluorescence images with a Nikon TE2000E fluorescence microscope.

To identify the laminar location of recorded cells (loaded with biocytin through whole-cell recording pipettes) after the recording, mice were deeply anesthetized with pentobarbital and perfused transcardially with cold saline followed by $4 \%$ paraformaldehyde. Coronal sections (70 $\mu \mathrm{m}$ thick) of the cortex were made using a vibratome (Microm HM 525 cryostat), and then were treated with Triton X-100 (0.5\%, v/v) and incubated with Alexa Fluor 488-conjugated streptavidin against biocytin. The laminae were roughly identified based on the density of cell stained with DAPI (4',6'-diamidino-2-phenylindole dihydrochloride). The average thickness of the mouse visual cortices was $996 \pm 43 \mu \mathrm{m}$ (eight mice), $1053 \pm 36 \mu \mathrm{m}$ (eight mice), and $1068 \pm 31 \mu \mathrm{m}$ (five mice) at P17-P19, $\mathrm{P} 27-\mathrm{P} 29$, and $\sim \mathrm{P} 60$, respectively, and correspondingly the layer 4 was located in the range of about $350-490,360-500$, and $360-500 \mu \mathrm{m}$. This laminar depth characterization is comparable to findings in previous studies (Li et al., 2012). Fluorescence images were acquired by a Nikon A1R confocal microscope with a $20 \times$ objective lens.

Modeling simulation. In the model, synaptic modifications were governed by a homeostatic learning rule, namely the BCM rule (Bienenstock et al., 1982; Intrator and Cooper, 1992). A form of the BCM rule with lateral inhibition (Intrator and Cooper, 1992) and synaptic competition (Stent, 1973; Miller, 1996) was used, as detailed below. Formally, the model consisted of $n=100$ inputs and $n_{\text {out }}=25$ cortical output neurons (having output rate $r_{j}$ ). Output neurons additionally received lateral inhibition. The activity of the $j$ th neuron without lateral inhibition $v_{j}$ at a time $t$ was given by Equation 1: $v_{j}=\sigma\left(w_{j} x_{t}+\xi_{j}\right)$, where $w_{j}$ is the weight vector integrating the input rates $x_{t}$, and $\xi_{j}$ is a small Gaussian noise term (mean, $0 ; \mathrm{SD}, 0.01)$. We set $\sigma(z)=[\tanh (2.5 z-0.5)+1] / 2$ as a sigmoid activation function. The output neurons received direct inputs as well as lateral inhibition according to the following Equation 2:

$$
r_{j}=\sigma\left(\mathbf{w}_{j} \mathbf{x}_{t}+\xi_{j}-\frac{\eta}{n} \sum_{k \neq j} v_{k}\right)
$$

Mutual lateral inhibition strength was regulated by the parameter $\eta$ (set to 0.55 in the simulation). Because of the lateral competition, cortical neurons have a tendency to learn different aspects of the visual inputs (e.g., different orientations) and weights tend to be sparser. However, in principle the set of possible fix-points does not change compared with the BCM rule without lateral inhibition (Castellani et al., 1999). The time step $t$ in this framework would correspond to the temporal average within a small temporal window (e.g., tens of milliseconds). The rate within this temporal window was considered as input to the visual neurons. In our simulation, each neuron received $n=100$ inputs, with the first $60 \%$ input synapses originating from the contralateral eye and the rest from the ipsilateral eye. An input pattern $y_{k}$ (a vector of 100 dimensions) consisted of sparse activation of two of the input neurons, so that activated inputs had a relatively higher mean firing rate $r$. Simultaneous activation simulated a small amount of signal correlation in the visual inputs. For simplicity, we assumed that activated input neurons do not overlap between different patterns in the pool as well as between ipsilateral and contralateral pathways. In detail, we set $y_{k i}=r$ if $|i / 2|=k$ and otherwise zero $(k=1, \ldots, 50)$. The rate of the activated inputs $r$ was drawn from Gaussian distribution of mean 0.5 (with SD of 0.05 ; note that all rates of the model could be scaled arbitrarily). Input patterns were predetermined at the beginning of a simulation repeat and thus initially generated 30 purely contralateral $(k=1, \ldots, 30)$ and 20 purely ipsilateral input patterns $(k=31, \ldots, 50)$. During simulation, one of the 50 input patterns from the pool was selected (i.e., $k$ was randomly chosen each step) and it was set $x_{t}=y_{k}+\xi$, with Gaussian noise $\xi$ (mean, 0.002; SD, 0.15 ). The noise modeled fluctuations originating from spontaneous background activity and variations in the input. Note that because of the noise, input rates could in principle be negative, which accounted for a small amount of feed-forward inhibition.

In this abstract framework, we assumed that for a given $t$ during the pre-CP, only one of both eyes carried visual information (i.e., activated single inputs), and thus set the pool of input patterns as described above. Note that if the contralateral eye was activated at time $t$, in the next time step, $t+1$, the ipsilateral eye might deliver inputs. Thus, our framework modeled a temporal separation in the inputs from both eyes as our experiments indicated. During the $\mathrm{CP}$, in which inputs from both eyes were observed to be highly coincident in experiments, we simply added $60 \%$ of all ipsilateral patterns to corresponding contralateral patterns, so that a part of the input arrived from both eyes together (compare with Fig. $10 A)$. In other words, the pool of patterns during CP consisted of 12 joint patterns, i.e., $y_{k}+y_{k+30}(k=1, \ldots, 12)$, together with the remaining 18 purely contralateral and 8 ipsilateral patterns as before. The total average input rate was thus somewhat higher in the $\mathrm{CP}$, reflecting the increase of rate in the experimental data (drifting grating-evoked spiking rates of $\mathrm{V} 1$ binocular cells at CP: contralateral, $7.4 \pm 1.4 \mathrm{~Hz}$; ipsilateral, $5.6 \pm 0.9 \mathrm{~Hz}$, $n=70$; at pre-CP: contralateral, $4.4 \pm 0.9 \mathrm{~Hz}$, ipsilateral, $3.4 \pm 0.7 \mathrm{~Hz}$, $n=81$ ). During the MD in pre-CP or CP, the same input patterns were taken, respectively, but inputs from the contralateral eye were set to zero. In addition, the background noise fluctuations were strengthened somewhat for contralateral inputs (mean, 0.002; SD, 0.21).

The simulation ran for 50,000 steps in each of the three periods (pre$\mathrm{CP}, \mathrm{CP}, \mathrm{MD})$. In response to the given input at time step $t$, output neurons would adapt their weights. If we label the subthreshold potential in Equations 1 and 2 with $v_{j}^{*}$ and $r_{j}^{*}$, so that Equations 1 and 2 become $v_{j}=\sigma\left(v_{j}^{*}\right)$ and $r_{j}=\sigma\left(r_{j}^{*}\right)$, the weight update rule reads according to the following Equation 3 (cf. Intrator and Cooper, 1992):

$$
\tau_{w} \Delta \mathbf{w}_{j}=\phi_{j} \mathbf{x}_{t}-\sum_{k \neq j} \phi_{k} \sigma^{\prime}\left(v_{k}^{*}\right) \mathbf{x}_{t}
$$

with the abbreviation $\phi_{j}=r_{j}\left(r_{j}-\bar{r}_{j}^{2}\right) \sigma^{\prime}\left(r_{j}^{*}\right)$. The variable threshold that is typical for a BCM rule was determined by the running average of the output firing rate $\bar{r}$ (computed on a time scale of 1000 steps). The time constant for the weight update was $\tau_{w}=50$ in the simulations. To avoid negative weights, we implemented a hard threshold, so that weights that would fall below zero after the weight update were set to zero. Synaptic competition was implemented by normalizing the length of the weight vector of each cortical neuron to 1 after each update step. Initially, weights were set to a uniform random numbers.

Data analysis. For the analysis of subthreshold PSP responses, action potentials were truncated at spike threshold by linear interpolation (Anderson et al., 2000). Due to relatively high noise level of membrane potentials during in vivo recording, we detected the PSP onset of a V1 binocular cell using the averaged PSP from many trials. The onset of PSP is defined by the time when the averaged PSP increases above the noise level of membrane potentials. This detection is not sensitive enough for synaptic events induced by single input spike. The latency was calculated with a custom MatLab program using an adaptive method as follows. Averaged PSPs were first smoothed by low-pass filtering $(80 \mathrm{~Hz})$, and then the rate of membrane potential change $(d V / d t)$ was calculated at each discrete time step. An adaptive algorithm was used to detect the onset timing point where the $d V / d t$ value reached a threshold of $0.02-0.1$ $\mathrm{mV} / \mathrm{ms}$ and retained above the threshold for a duration of $\geq 15 \mathrm{~ms}$. Moreover, the nonparametric bootstrap resampling method (Meister et al., 2013) was adopted to estimate the trial-to-trial variability of the onset latency of the averaged PSP. Bootstrapped average PSP traces for each spatial phase were computed by first resampling 40 repetitions with replacement from the original 40 trials and then subsequently averaged. From bootstrapped average traces, the onset latency was calculated using the same onset detection algorithm. The SD across the latencies of 500 bootstrapped average PSPs was used to estimate the trial-to-trial variability (Fig. $1 A-C$, bottom). For evoked single-unit spike response, the onset 
A Static Gratings
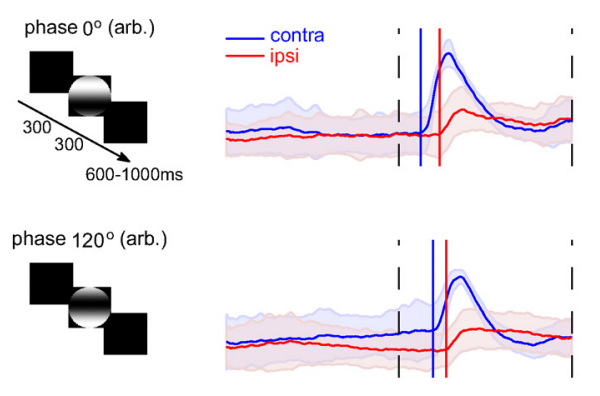

B

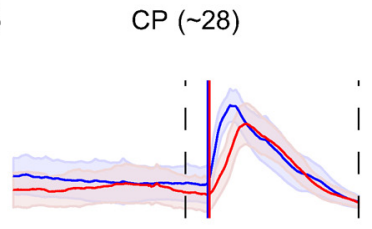

C

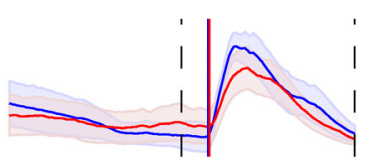

Adult $(\sim 60)$

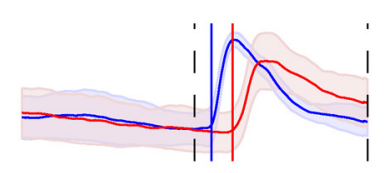

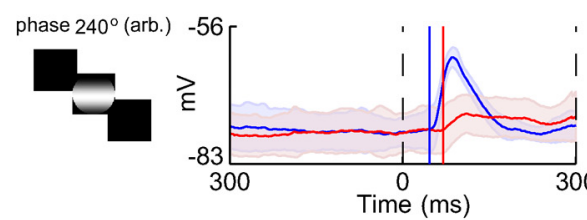
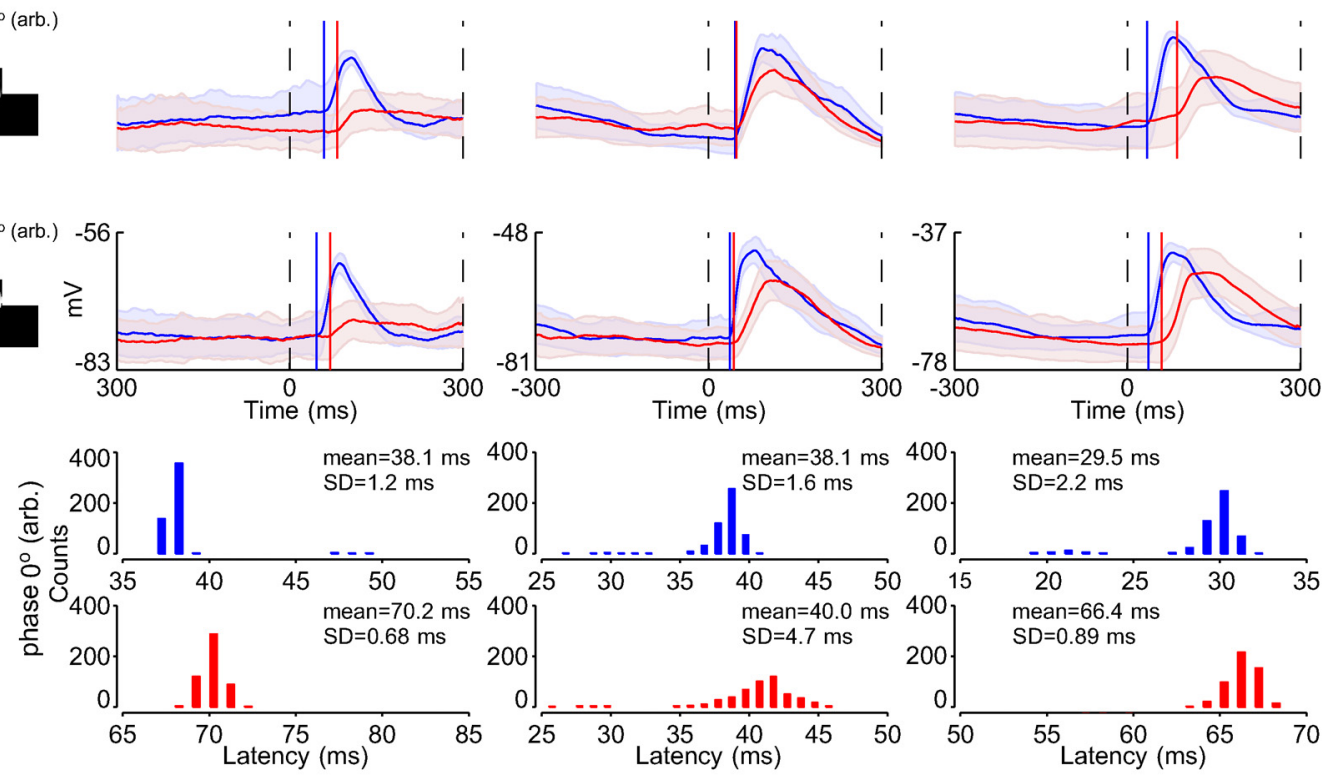

D

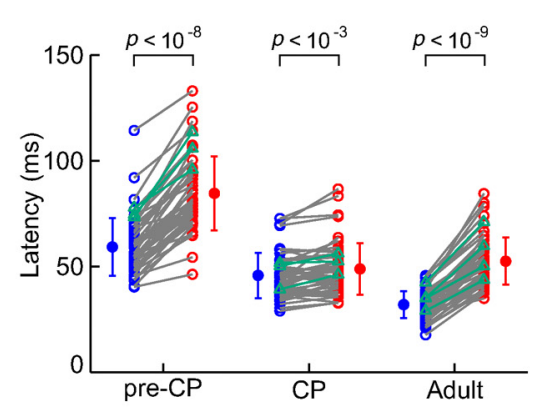

E

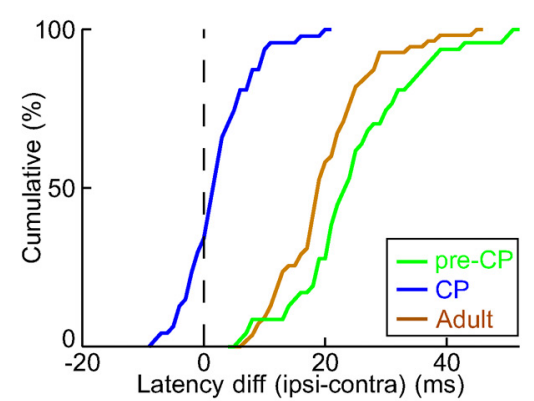

Figure 1. Critical period-specific increase of the level of coincidence of binocular synaptic inputs. $A$, Solid curves are averaged subthreshold PSP responses of a binocular cell during the pre-CP, evoked by full-field static gratings (at 3 different spatial phases, left) presented alternately to contralateral (blue) and ipsilateral (red) eye, in a mouse under ketamine/medetomidine anesthesia. Shading indicates trial-to-trial SD of membrane potential. Dashed lines represent times of stimuli ON and OFF, and solid blue and red lines indicate the onset times of contralateral and ipsilateral PSPS, respectively. Bottom, Distribution of onset latencies calculated by bootstrapping 500 times. $\boldsymbol{B}, \boldsymbol{C}$, Same as $\boldsymbol{A}$, except for binocular cells recorded during the (P $(\boldsymbol{B})$ and adulthood (C). D, Summary of the mean latency of evoked PSPs from experiments shown in $\boldsymbol{A}-\boldsymbol{C}$. Data connected with a line are from the same cell. Filled circles with error bars: mean \pm SD. Triangles, Data from animals under pentobarbital anesthesia. $p$ values are calculated by the Wilcoxon signed-rank test. $\boldsymbol{E}$, Cumulative distribution of the ipsi-contra latency difference in pre- $C P, C P$, and adulthood. Significant difference was found between $\mathrm{CP}$ and pre- $\mathrm{CP}\left(p<10^{-16}\right.$, Kolmogorov-Smirnov test), $\mathrm{CP}$ and adulthood $\left(p<10^{-17}\right)$.

latency was defined as the time at which the spike rate first deviates from the baseline (calculated from the blank period) by 1.96 folds of SD, following a method described previously (Zhang et al., 2008).

For each recorded V1 cell, the RF was measured by reverse correlating the averaged PSPs with the flashing squares in the $8 \times 8$ grid, and its spatial and temporal properties were analyzed following a method developed by Mazer et al. (2002). The temporal RF (tRF) was represented by the time course of the STRF slice variance (see Fig. 3; Mazer et al., 2002). The onset latency of tRF could be determined by the rising speed of slice variance, a method similar to that for defining evoked PSP onset time. The spatial RF was calculated by fitting the frame with the largest variance with the 2D Gaussian functions expressed in the following equations:

$$
\begin{gathered}
R F(x, y)=A e^{-\left(\frac{x^{\prime 2}}{2 \sigma_{x}^{2}}+\frac{y^{\prime 2}}{2 \sigma_{y}^{2}}\right)} \\
x^{\prime}=\left(x-x_{0}\right) \cos \theta+\left(y-y_{0}\right) \sin \theta
\end{gathered}
$$

$$
y^{\prime}=-\left(x-x_{0}\right) \sin \theta+\left(y-y_{0}\right) \cos \theta
$$

Where $A$ is amplitude of the RF response, $\sigma_{x}$ and $\sigma_{y}$ determined the two axes of RF, and $\theta$ was the orientation of the RF. The spatial territory of the RF was estimated based on two times the SD of the fitted 2D Gaussian.

For each recorded visual cell in V1 binocular zone, the degree of OD was quantified by an index: ODI $=(C-I) /(C+I)$; where $C$ and $I$ represent the amplitude of subthreshold PSPs or rates of suprathreshold spike evoked by the visual stimuli presented to the contralateral or ipsilateral eye, respectively, after a baseline subtraction. In the modeling simulation, $C$ and $I$ represent the weights of contralateral and ipsilateral synapses, respectively. The ODI ranges from +1 for neurons driven exclusively by the contralateral eye to -1 for those driven exclusively by the ipsilateral eye. The OD distribution of binocular cells pooled from all animals was presented by the classical seven-point classification scheme 
(Hubel and Wiesel, 1970). Correspondingly, the contralateral bias index (CBI) was then calculated according to the following formula: $\mathrm{CBI}=$ $\left[\left(n_{1}-n_{7}\right)+(2 / 3)\left(n_{2}-n_{6}\right)+(1 / 3)\left(n_{3}-n_{5}\right)+N\right] / 2 N$, where $n_{x}$ were numbers of cells with OD category equal to $x$ and $N$ was the total number of examined cells (Gordon and Stryker, 1996; Hensch et al., 1998).

The trial-to-trial variability of spike response evoked by monocular or binocular stimuli with full-screen static gratings (at three different spatial phases) was evaluated with the Fano factor (FF), which is defined as the variance of the spike count divided by the mean (Shadlen and Newsome, 1998; Kara et al., 2000). For this analysis, we chose a 50 ms time window and $10 \mathrm{~ms}$ sliding step. For each recorded cell, the values of FF were calculated from trials with static gratings at three different spatial phases, respectively, and then the mean FF was used to represent the evoked spiking reliability of one cell.

Data are presented as mean \pm SD unless stated otherwise, and the statistical significance was tested with the Wilcoxon signed-rank test, Wilcoxon rank-sum test, or Kolmogorov-Smirnov test.

\section{Results}

All electrophysiological recordings were done in the binocular zone of the developing V1 in anesthetized mice aged P17-P19, $\mathrm{P} 27-\mathrm{P} 29$, or $\sim \mathrm{P} 60$, referred to as the periods before, during, and after the CP of experience-dependent OD plasticity, respectively (Gordon and Stryker, 1996). In most recording experiments, we first used full-screen drifting sinusoidal gratings with varying orientations (at spatial frequency of $0.02 \mathrm{~Hz} /$ degree and temporal frequency of $2 \mathrm{~Hz}$ ) to determine the preferred orientation for the input from each eye in a binocular cell (B. S. Wang et al., 2010), and then performed further experiments using static or drifting gratings with the optimal orientation.

\section{CP-specific emergence of coincident binocular synaptic inputs}

We conducted in vivo whole-cell recordings from V1 binocular cells to systematically examine the temporal correlation between the synaptic inputs originating from the two eyes before, during, and after the CP. Visually evoked spikes and subthreshold PSPs were recorded in cortical binocular cells in mice under ketamine/ medetomidine anesthesia. To precisely quantify the synaptic inputs originating from the contralateral and ipsilateral eyes, we presented full-screen static gratings with optimal orientation of the recorded binocular cell using three different spatial phases (equally spaced from 0 to $360^{\circ}$ ), alternately presented to either eye (Fig. 1A, left). The peak amplitude and onset latency of the evoked contralateral or ipsilateral PSPs were measured to determine the degree of $\mathrm{OD}$ and binocular input coincidence (see Materials and Methods). In mice at $\sim$ P18 (pre-CP), P28 (CP), and P60 (adult), monocular PSPs of the V1 binocular cells were reliably evoked in response to static grating stimulus to the contralateral or ipsilateral eye in the V1 binocular cell, regardless of highly variable baseline of membrane potentials, and their onset timing showed relatively low trial-to-trial variability (Fig. $1 A-C$, traces). The latter point was further confirmed by an analysis of onset latencies of the bootstrapped average PSPs (see Materials and Methods), as shown by a relatively narrow range of these onset latencies from sample cells recorded in three different periods (Fig. $1 A-C$, histograms). By analyzing the onset latency of averaged PSPs, we found that the PSP responses evoked by the static grating stimuli presented to the contralateral eye preceded those of the ipsilateral eye by $25.4 \pm 10.0 \mathrm{~ms}$ (mean $\pm \mathrm{SD}$ ) in P17-P19 mice ( $n=47$ cells in 32 mice; Fig. $1 A, D, E)$, while in P27-P29 mice, the temporal difference of the PSP onset latency between binocular inputs (ipsi-contra latency difference) markedly decreased to $3.1 \pm 5.6 \mathrm{~ms}(n=47$ cells in 24 mice; Fig.
$1 B, D, E)$, indicating a considerably higher level of coincidence between binocular synaptic inputs during the peak of CP. By contrast, this transiently increased binocular coincidence of contralateral and ipsilateral eye inputs declined again when the mice reached adulthood $(\sim \mathrm{P} 60)$, with the ipsi-contra latency difference increasing to $20.6 \pm 7.8 \mathrm{~ms}(n=55$ cells in 22 mice; Fig. $1 C-E)$. These results directly demonstrated an emergence of temporal coincidence between synaptic inputs from the two eyes to V1 binocular cells during the CP. Moreover, the ipsi-contra latency difference in mice at the beginning of CP (P21) was $17.6 \pm$ $6.1 \mathrm{~ms}$ ( $n=10$ cells in four mice), showing an intermediate value between the pre-CP and CP. This result suggested a gradual increase of binocular input coincidence from the beginning to peak of CP. Averaged results (Fig. 1D) further indicated that, with development, the onset latency of evoked PSPs to contralateral eye stimuli decreased from $59.1 \pm 13.7 \mathrm{~ms}$ in the pre-CP to $45.7 \pm 10.7 \mathrm{~ms}$ in the $\mathrm{CP}\left(p<10^{-6}\right.$, Wilcoxon rank-sum test $)$, and subsequently reduced to $31.9 \pm 6.4 \mathrm{~ms}$ in the adult $(p<$ $\left.10^{-10}\right)$. Meanwhile, for ipsilateral inputs, onset latency in cortical binocular cells initially decreased from $84.5 \pm 17.5 \mathrm{~ms}$ in the pre-CP to $48.8 \pm 12.2 \mathrm{~ms}$ in the $\mathrm{CP}\left(p<10^{-13}\right)$ and then did not exhibit further reduction in adult $(52.4 \pm 11.1 \mathrm{~ms}, p=0.05)$. Thus the observed increase of binocular input coincidence from pre-CP to $\mathrm{CP}$ is due to a larger reduction of ipsilateral input latency, whereas the decreased level of coincidence in adults is caused by a further reduction of contralateral input latency while ipsilateral input latency remains stable (Fig. 1D). Similar results were observed in mice under pentobarbital anesthesia (Fig. 1D, triangles), indicating that the $\mathrm{CP}$-specific emergence of coincidence of binocular synaptic inputs was not anesthetic-specific.

V1 cells show increasing latency in visual responses when visual stimuli decrease the contrast level (Carandini et al., 1997; Oram, 2010) or luminance intensity (Tucker and Fitzpatrick, 2006). Due to the preference of low spatial-frequency visual inputs of the mouse vision, we only tested whether the intensity of stimulus luminance affects the ipsi-contra latency differences of V1 binocular cells. Three mean luminance intensities, $40 \mathrm{~cd} / \mathrm{m}^{2}$ (100\%), $20 \mathrm{~cd} / \mathrm{m}^{2}(50 \%)$, and $10 \mathrm{~cd} / \mathrm{m}^{2}(25 \%)$, were used for the full-field static gratings (Fig. $2 A$, left). The results showed that in mice at all three different stages, stimuli with lower luminance elicited PSP responses with much longer onset latency and smaller amplitude for contralateral or ipsilateral eye stimuli (Fig. $2 A-C)$. However, the ipsi-contra latency difference did not differ significantly among the luminance conditions in the pre-CP $(23.5 \pm 4.2,24.4 \pm 6.3$, and $26.1 \pm 9.3 \mathrm{~ms}$ for 100,50 , and $25 \%$ luminance, $n=8$ cells from six mice), CP (1.0 $\pm 3.8,2.6 \pm 4.2$, and $5.5 \pm 7.1 \mathrm{~ms}, n=12$ cells from eight mice), and adult (21.9 \pm 4.0, $21.6 \pm 8.8$, and $24.7 \pm 7.5 \mathrm{~ms}, n=19$ cells from 11 mice). These results suggest that the observed increase in the binocular input coincidence in V1 binocular cells during the $\mathrm{CP}$ is not affected by the change of visual stimulation features.

Taken together, these results indicate that V1 cells exhibit a higher level of binocular synaptic input coincidence during the $\mathrm{CP}$, which is independent on the intensity of visual inputs.

\section{Binocular input coincidence quantified by spatiotemporal receptive field properties}

Full-field visual stimuli often exert complex surround modulation of visual responses in cortical cells (Hubel and Wiesel, 1968; Van den Bergh et al., 2010), such as surround suppression (Bair et al., 2003; Smith, 2006). Although the effects were shown to be moderate under anesthesia (Adesnik et al., 2012), surround suppression may affect the onset latency of evoked PSPs and thus also 
A
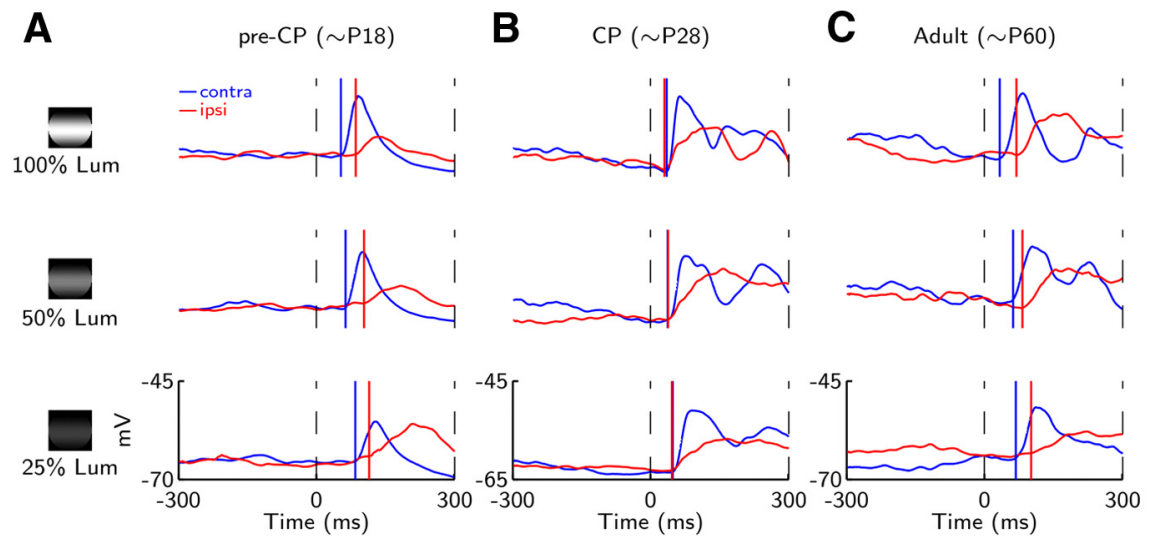

D

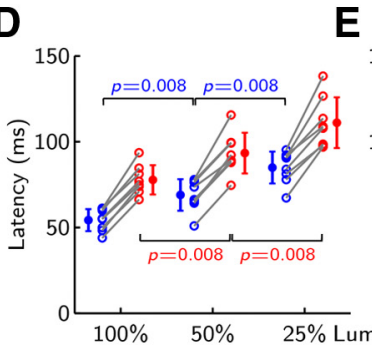

E

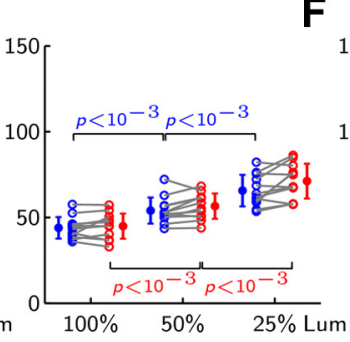

Figure 2. Effect of luminance of visual stimuli on the PSP response latency. $\boldsymbol{A}-\boldsymbol{C}$, Example contralateral (blue) and ipsilateral pre- $C P(\boldsymbol{A}),(\boldsymbol{C}(\boldsymbol{B})$, and adult $(\boldsymbol{C})$ mice. $\boldsymbol{D}-\boldsymbol{F}$, Summarized results from the experiments shown in $\boldsymbol{A}-\boldsymbol{C}$. Data connected with a line are from the same cell. Filled circles with error bars: mean \pm SD. $p$ values were calculated using the Wilcoxon signed-rank test.

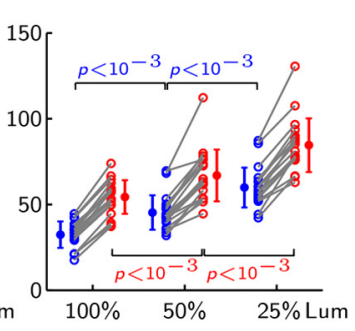
(red) PSPs evoked by one of three spatial phases of static gratings with 100,50 , and $25 \%$ luminance in the binocular cell from

Thus, the above experiments using various visual stimuli and measurement parameters all consistently suggest a high level of coincidence of binocular synaptic inputs to cortical binocular cells specifically during the $\mathrm{CP}$ in the developing V1.

\section{Unchanged binocular input coincidence across layers $2 / 3$ and 4}

The latency of visually evoked responses in V1 varies across the cortical laminae (Maunsell and Gibson, 1992). In general, layer 4 is the recipient layer of thalamocortical projections and transfers information to layer 2/3 (Gilbert and Wiesel, 1979; Douglas and Martin, 2004). We next examined whether the $\mathrm{CP}$-specific increase of binocular input coincidence depends on the laminar locations of V1 binocular cells. In this set of experiments, we reconstructed the neuronal morphology of 33 recorded cells (intracellularly loaded with biocytin) after whole-cell recording in pre-CP (11 cells from eight mice), $\mathrm{CP}$ ( 13 cells from eight mice), and adult (nine cells from five mice) mice. As shown for example cells in Figure $4 A$, these reconstructed cells located primarily within layers $2 / 3$ and 4 , displaying typical the measurement of binocular input coincidence when full-field visual stimuli are used. To quantify this possibility, we measured STRF properties of binocular cells for the contralateral and ipsilateral inputs, on the basis of subthreshold PSPs. In this set of experiments, we followed a previous method (DeAngelis et al., 1993) to map the STRFs of binocular cells using an $8 \times 8$ grid of bright squares (pixels) presented in a sparse noise mode to either eye (see Materials and Methods). We calculated the onset latency of individual pixel-evoked PSPs within the boundary of the spatial RF, and then compared the mean latencies between the contralateral and ipsilateral RFs. We found that the cumulative distribution of onset latencies of individual pixel-evoked PSPs indicated a reduction of the ipsi-contra latency difference during the $\mathrm{CP}$ in comparison with pre-CP or adult mice (Fig. $3 A-C$, top, $D$ ). The averaged difference of the mean latency of single pixelevoked PSPs between contralateral and ipsilateral spatial RFs was $6.0 \pm 9.4 \mathrm{~ms}$ ( $n=18$ cells in 13 mice), $28.3 \pm 8.3 \mathrm{~ms}(n=7$ cells in seven mice), and $21.5 \pm 7.5 \mathrm{~ms}$ ( $n=17$ cells in 11 mice) in CP, pre-CP, and adult, respectively.

When the temporal RF was analyzed to determine the onset latency of RF emergence based on the variance of membrane potentials in STRF slices at discrete times (Mazer et al., 2002; see Materials and Methods), we found that contralateral and ipsilateral tRFs of recorded binocular cells emerged nearly simultaneously during the CP (Fig. 3B, bottom, D), but showed a large temporal gap in their emergence during the pre-CP or adulthood (Fig. $3 A, C$, bottom, $D$ ). The difference of onset latency between contralateral and ipsilateral tRFs was $8.0 \pm 9.8 \mathrm{~ms}$ during the $\mathrm{CP}$, but $34.0 \pm 10.1 \mathrm{~ms}$ and $21.4 \pm 6.0 \mathrm{~ms}$ in pre-CP and adult, respectively. Thus, these results from the temporal RF measurements agree well with those observed from pixel-PSP responses within spatial RFs (Fig. 3E). Both measurements consistently indicate an increased level of coincidence of binocular synaptic inputs in cortical binocular cells during the $\mathrm{CP}$. neuronal morphology of pyramidal cells with apparent apical and basal dendrites. Moreover, we also estimated the subpial depth of most other recorded cells on the basis of the calibration between the microelectrode penetration depth (read from the manipulator) and the precise depths of reconstructed cells in mice of the same age. Consistent with previous studies (Maunsell and Gibson, 1992), the visual PSP responses of layer $2 / 3$ cells evoked by full-field static grating (100\% luminance) exhibited relatively longer response latency compared with layer 4 cells in mice at all three developmental stages (Fig. $4 B$, red and gray circles for the reconstructed and other V1 cells, respectively). However, we found that the ipsi-contra latency difference was retained at nearly same values across the layers $2 / 3$ and 4 of pre$\mathrm{CP}, \mathrm{CP}$, and adult mice (Fig. $4 \mathrm{C}$ ). On average, the values of the ipsi-contra latency difference for layers 4 and $2 / 3$ were $23.6 \pm 9.7$ and $25.5 \pm 9.7 \mathrm{~ms}$ in pre-CP $(p=0.75), 2.4 \pm 6.0$ and $3.0 \pm 5.7$ $\mathrm{ms}$ in CP $(p=0.80)$, and $21.2 \pm 4.7$ and $20.7 \pm 8.8 \mathrm{~ms}$ in adult $(p=0.41)$. Thus, the binocular cells in layers $2 / 3$ and 4 all showed a high level of binocular synaptic input coincidence specifically during the CP. Since the output of layer 4 cells primarily projects to layer $2 / 3$, it is likely that the CP-specific binocular input coincidence observed in layer $2 / 3$ cells may be inherited from layer 4 .

\section{Tight association between emergence of binocular input coincidence and the $\mathrm{CP}$ onset}

The timing of the $\mathrm{CP}$ onset is known to be regulated by the maturation of cortical GABA transmission (Hensch, 2005; Espinosa and Stryker, 2012). For example, elevating GABA transmission by daily infusion of $\mathrm{DZ}$, a benzodiazepine agonist of $\mathrm{GABA}_{\mathrm{A}}$ receptors, to the premature cortex (for $2-5 \mathrm{~d}$ ) during the pre- $\mathrm{CP}$ rapidly triggers an induction of the $\mathrm{CP}$. This precocious $\mathrm{CP}$ induced by the DZ infusion provides a window to examine whether the emergence of binocular input coincidence is tightly associated with the onset of CP. Consistent with previous findings, we 
A

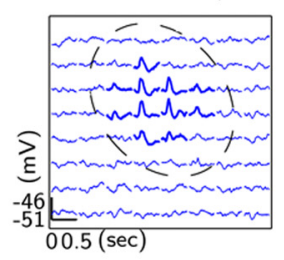

pre-CP ( P18)

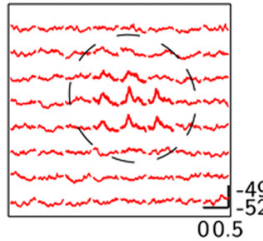

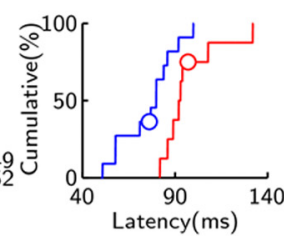

$160 \mathrm{~ms}$
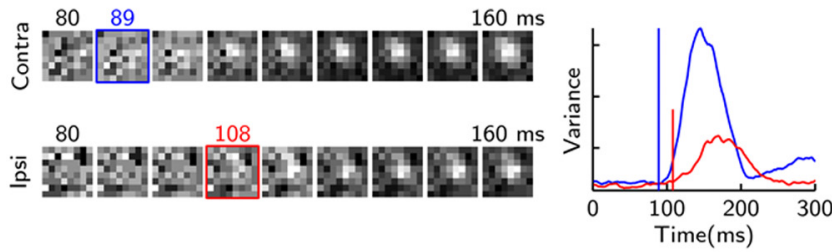

C
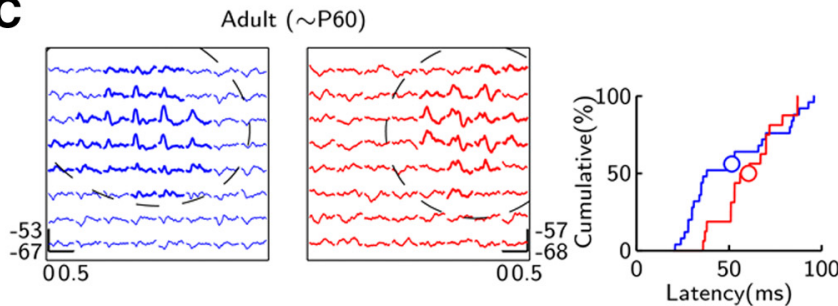

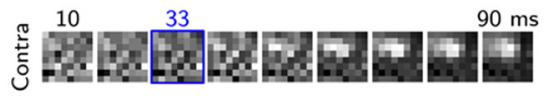
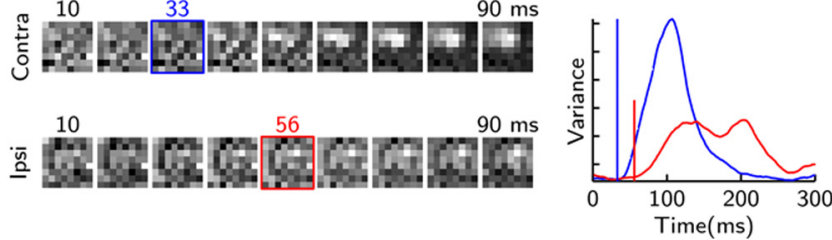

B

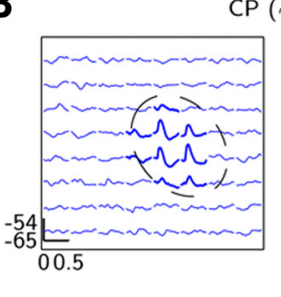

$\mathrm{CP}(\sim \mathrm{P} 28)$
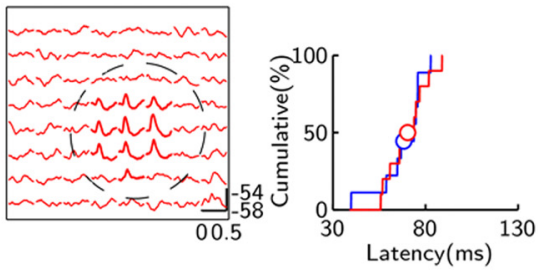

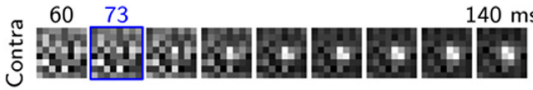
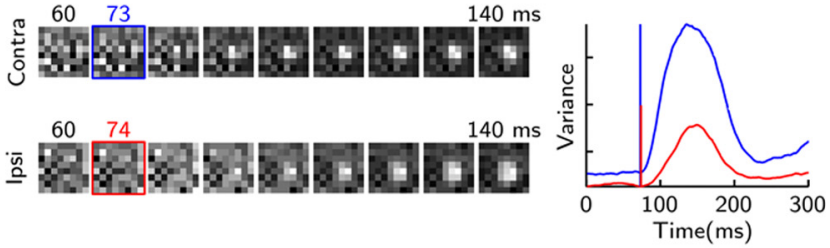

D
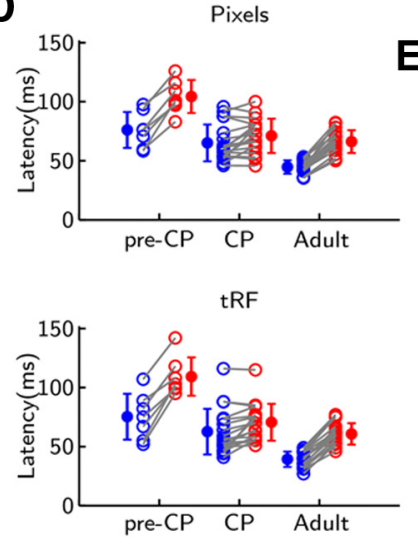

E

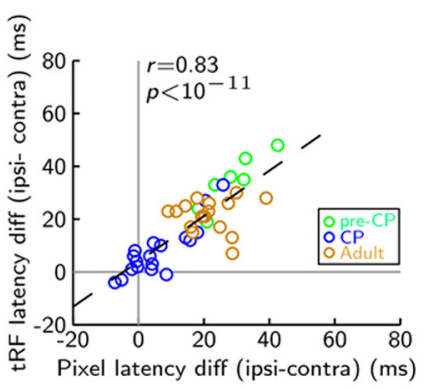

Figure 3. Coincidence of binocular synaptic inputs quantified by subthreshold STRFs. $A$, Top left, Contralateral (blue) and ipsilateral (red) spatial RFs (outlined by dashed lines) of a binocular cell recorded in the pre-CP. Top right, Cumulative distribution of the onset latencies of contralateral or ipsilateral PSPs evoked by single pixel stimuli within RFs, with open circles indicating the averages. Bottom left, Nine consecutive time frames of contralateral or ipsilateral tRFs in $10 \mathrm{~ms}$ intervals; membrane potentials at 64 pixel positions are coded by gray intensities. The onset times of contralateral and ipsilateral tRFs are indicated by thick blue and red boxes, respectively. Bottom right, Change in the variance of membrane potentials at 64 positions (binned at $1 \mathrm{~ms}$ ) over the time. Vertical blue and red lines, Onset times of contralateral and ipsilateral RFs, respectively. $\boldsymbol{B}$, $\boldsymbol{C}$, Same as $\boldsymbol{A}$ except binocular cells were examined in $(\boldsymbol{P}(\boldsymbol{B})$ and adult $(\boldsymbol{C})$ mice. $\boldsymbol{D}$, Summary of the mean onset latency measured from pixel-evoked PSPs (top) or tRFs (bottom). Filled circles with error bars: mean \pm SD. $E$, Correlation plot of the ipsi- contra latency difference measured from pixel-PSPs and tRFs. Dashed line, Linear regression fit.

found that direct enhancement of GABA transmission by brain infusion of DZ for $5 \mathrm{~d}$ during the pre-CP (P15-P19), but not the vehicle solution ( $50 \%$ propylene glycol, $49 \% \mathrm{H}_{2} \mathrm{O}$, and $1 \%$ DMSO) induced a precocious CP. This is shown by the OD shift of binocular cells after a $4 \mathrm{~d}$ deprivation of inputs from the contralateral eye, as indicated by changes of the classical seven-point histogram of $\mathrm{OD}$ and the $\mathrm{CBI}$ between mice with normal rearing and MD treatment in the pre-CP (Fig. 5A,B). Remarkably, such infusion of DZ also caused an earlier emergence of binocular input coincidence in binocular cells before the normal CP onset, with the temporal difference of PSP onset latency between binocular inputs (ipsi-contra) as small as $6.2 \pm 3.1 \mathrm{~ms}(n=15$ cells in six mice at P18; Fig. 5C). This result suggests that the coincidence of binocular synaptic inputs to cortical binocular cells is regulated by GABA inhibition. Enhancing GABA inhibition decreased the PSP onset latency for both contralateral and ipsilateral eyes compared with the latency of normal P17-P19 mice (Fig. 5C).

On the other hand, dark-rearing an animal from birth is known to delay the onset of CP and MD-induced OD plasticity (Mower, 1991; Fagiolini et al., 1994; Hensch, 2005). We reproduced a similar delay of the $\mathrm{CP}$ onset timing in our DR mice (Fig. $6 A)$. Surprisingly, we further observed that these DR animals also did not show an emergence of the coincidence of binocular inputs in V1 binocular cells examined at P27-P28 (Fig. 6C,D). At $\mathrm{P} 27-\mathrm{P} 28$, the synaptic response latency difference between the two eyes (ipsi-contra) was considerably larger in DR mice ( $21.5 \pm 11.5 \mathrm{~ms}, n=22$ cells in 11 mice; Fig. $6 C$ ) than in normalreared mice $(3.1 \pm 5.6 \mathrm{~ms})$. Moreover, we noticed that the PSP latency for the contralateral eye inputs was not affected by darkrearing (DR, $41.8 \pm 8.8 \mathrm{~ms}$ vs control $\mathrm{CP}, 45.7 \pm 10.7 \mathrm{~ms} ; p=$ 0.28 ), while that for the ipsilateral eye inputs after the darkrearing was still relatively high $(\mathrm{DR}, 63.3 \pm 13.6 \mathrm{~ms}$ vs control $\mathrm{CP}$, $48.8 \pm 12.2 \mathrm{~ms} ; p<10^{-4}$ ), suggesting a visual experiencedependent differential change of synaptic dynamics in contralateral and ipsilateral eye pathways.

We further found that the OD plasticity in DR mice could be rapidly rescued by daily infusion of DZ (for $4 \mathrm{~d}$ at P25-P28) immediately following the dark-rearing, as indicated by the OD shift of cells in the V1 binocular zone to the nondeprived eye after $4 \mathrm{~d}$ MD (Fig. 6B). Again, we also observed the rescuing effect of the emergence of binocular input coincidence in cortical binocular cells in the DR mice after infusion of DZ (Fig. $6 C, D$ ), with a value of the ipsi-contra latency difference of $2.8 \pm 7.9 \mathrm{~ms}(n=14$ cells in five mice). The DZ infusion in DR mice resulted in a large decrease in the PSP latency for the ipsilateral eye inputs (DR plus 


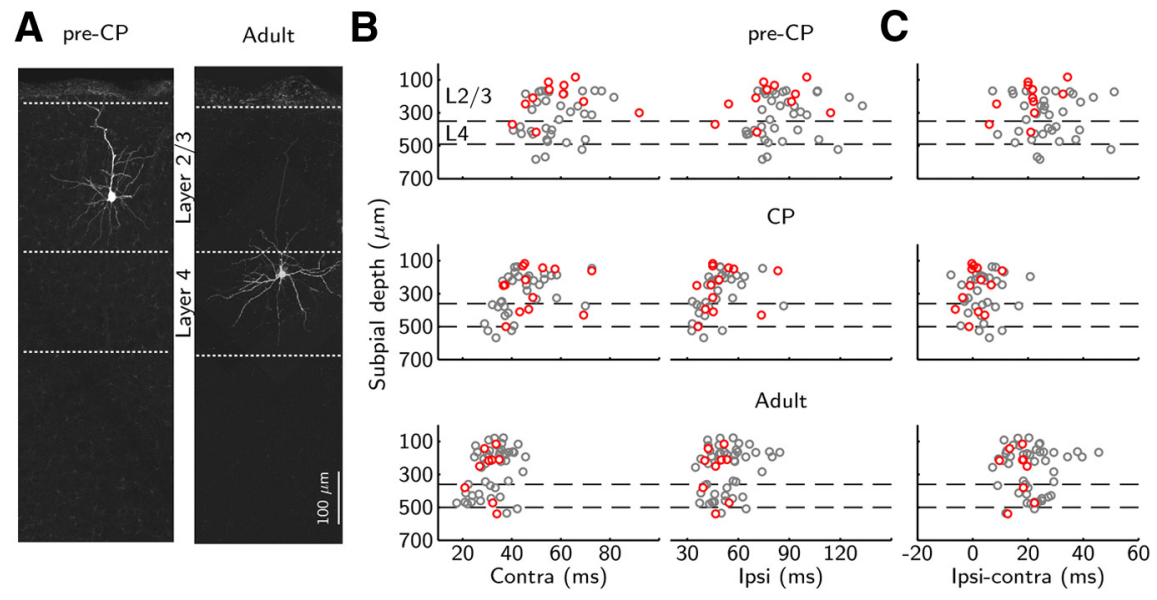

Figure 4. Dependence of laminar locations. $\boldsymbol{A}$, Fluorescence images showing two example reconstructed cells located in layers $2 / 3$ and 4 , respectively. The layer borders were indicated by dashed lines. $\boldsymbol{B}$, Plots of the PSP response latency versus the cortical depth of recorded cells from pre-CP, CP, and adult mice. Red circles, Data from biocytin-labeled cells. Gray circles, Data from cells with estimated cortical depths. $\boldsymbol{C}$, Plots of the ipsi- contra latency difference versus cell cortical depth.

DZ, $48.8 \pm 15.5 \mathrm{~ms}$ vs DR, $63.3 \pm 13.6 \mathrm{~ms} ; p=0.004)$, but little change in latency of the contralateral eye inputs (DR plus DZ, $46.0 \pm 21.1 \mathrm{~ms}$ vs DR, $41.8 \pm 8.8 \mathrm{~ms} ; p=0.87)$. As a control, brain infusion of the vehicle solution following the dark-rearing did not show any rescuing effects on the binocular input coincidence (Fig. $6 C, D)$ and the OD plasticity in developing V1 (Fig. $6 A)$. Thus, these results strongly suggest that the developmental emergence of binocular input coincidence in V1 is tightly associated with the onset of $\mathrm{CP}$, and that both processes are regulated by GABA inhibition.

\section{Disruption of binocular input synchrony during CP impaired OD plasticity}

We next examined whether specific disruption of the coincidence of binocular inputs affects the induction of MD-induced OD plasticity during the CP. To achieve precise temporal control of synaptic inputs from the two eyes on the scale of milliseconds, we used a transgenic mouse line expressing ChR2-EYFP under the control of the Thy1 promoter (Thy1-ChR2 mouse; Arenkiel et al., 2007). In the retina of Thy1-ChR2 mice, the light-activated cation channel ChR2 is specifically expressed in approximately onethird of the population of heterogeneous retinal ganglion cells (RGCs), which are distributed uniformly across the entire retina (Thyagarajan et al., 2010). A previous study showed that in these transgenic mice, the expression of ChR2-EYFP started at $\sim \mathrm{P} 8$ and confirmed that optogenetic activation of ChR2-expressing RGCs with blue LED light at P9-P10 already allowed precise control of RGC neuronal activity at high temporal resolution (Zhang et al., 2012). As shown by retinal sections from Thy1ChR2 mice (at P23) in Figure 7A, we consistently found that EYFP fluorescence signals were only detected in the ganglion cell layer and inner plexiform layer, indicating a specific expression of ChR2 in the soma and processes of RGCs.

We used two customized blue LED goggles, which were installed close to the front of the eyes, to activate these ChR2expressing RGCs. First, we tested whether the goggles were capable of providing synchronous or asynchronous activation of eye inputs to V1 binocular cells at the time order of milliseconds in these transgenic mice. We found that single $5 \mathrm{~ms}$ pulse of blue LED light itself could evoke cortical PSPs in V1 binocular cells in P22-P27 wild-type (WT) mice through activation of normal roddriven or cone-driven pathway, but asynchronous pulses of blue light at $50 \mathrm{~ms}$ intervals to the contralateral and ipsilateral eyes resulted in an inseparable PSP response (Fig. 7B, top). By contrast, in Thy1-ChR2 mice, the same pulses evoked faster PSPs in cortical binocular cells, which accurately followed the timing of asynchronous light pulses given to the two eyes (Fig. 7B, bottom). Moreover, extracellular recordings showed that when the same train of asynchronous light pulses was applied to the contralateral and ipsilateral eyes, two peristimulus time histogram (PSTH) peaks following the asynchronous timing were found in $\sim 63 \%$ of the recorded cortical cells (12 of 19 cells; Fig. 7C, left) in Thy1-ChR2 mice, but only one peak for most recorded cells in WT mice ( 11 of 15 cells; Fig. 7C, left). When delivering synchronous pulses to both eyes, Thy1-ChR2 mice exhibited a much higher mean spike rate of V1 binocular cells compared with WT (Thy1-ChR2: $82.2 \pm 8.1 \mathrm{~Hz}$, mean \pm SEM; $n=15$ in three mice; WT: $42.4 \pm 4.2 \mathrm{~Hz}, n=19$ in four mice; $p<10^{-3}$, Wilcoxon rank-sum test). These results demonstrated that despite of the existence of conventional rod-andcone pathways, direct activation of the ChR2-expressing RGCs could initiate synchronous or asynchronous activation of afferent inputs from the two eyes to V1 cells with high efficiency and temporal precision (in the millisecond range) in transgenic Thy 1ChR2 mice.

After these control experiments, we examined whether disruption of coincidence of synaptic inputs from the two eyes during the CP impairs the MD-induced OD plasticity. Because the observed temporal difference between contralateral and ipsilateral eye inputs was $\sim 20-30 \mathrm{~ms}$ in V1 binocular cells of both pre-CP and adult mice (Figs. 1, 4), we chose a $50 \mathrm{~ms}$ delay in the optogenetic activation between the two eyes. Each stimulus block consisted of five light pulses ( $5 \mathrm{~ms}$ duration, at $2.5 \mathrm{~Hz}$ ), and interblock interval was set to $5 \mathrm{~s}$. Chronic $50 \mathrm{~ms}$ asynchronous conditioning started on P22 ( $1 \mathrm{~d}$ after the beginning of CP) in Thy1-ChR2 mice for $4 \mathrm{~d}$ (12 h conditioning per day) in a dark environment, followed by the removal of the goggles and $4 \mathrm{~d}$ of monocular deprivation (Fig. $8 \mathrm{~A}$, diagram). Interestingly, while asynchronous conditioning did not significantly change the OD distribution of binocular V1 cells in Thy1-ChR2 mice (Fig. 8B, top, $D$ ), it abolished the MD-induced OD shift of cortical visual cells during the $\mathrm{CP}$ (Fig. $8 B, D$ ). This result strongly suggests that disruption of the coincidence of binocular inputs in V1 during the CP impairs the OD plasticity, underlining the critical importance of input coincidence for CP plasticity. Whole-cell recording from cortical binocular cells in Thy1-ChR2 mice further showed that after $4 \mathrm{~d}$ asynchronous conditioning, the latency difference of contralateral and ipsilateral PSPs again increased to $28.5 \pm 9.6$ $\mathrm{ms}$ ( $n=9$ cells in four mice) on P26, a value close to that found in normal-reared Thy1-ChR2 mice at the beginning of CP (P21, $19.4 \pm 8.3 \mathrm{~ms}, n=10$ cells in three mice; Fig. $8 E$ ). These results suggest that the asynchronous conditioning during the CP may impede the normal experience-dependent development of binocular input coincidence in V1 binocular cells. The dramatic reduction of binocular input coincidence following the asynchronous conditioning may account for the absence of normal $\mathrm{MD}$-induced OD shift during the CP. By contrast, synchronous 
A
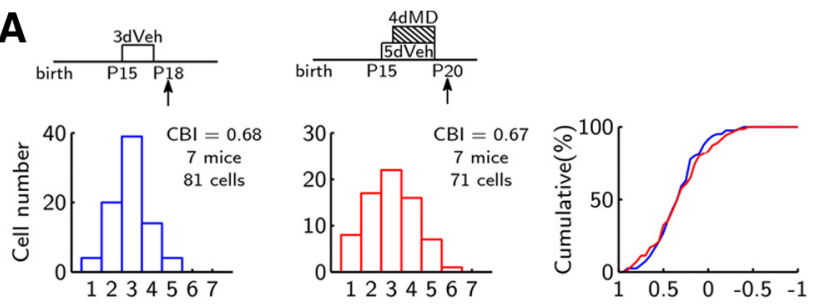

B
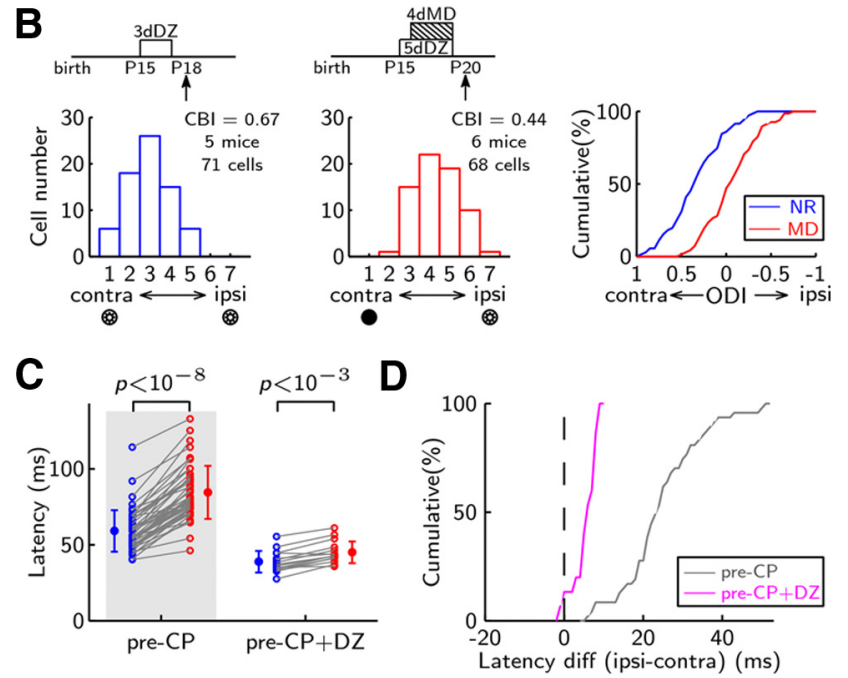

Figure 5. Brain infusion of $D Z$ causes a precocious emergence of binocular input coincidence and OD plasticity in the pre-CP. $A, B$, seven-point histograms (left two panels) and the cumulative percentage distribution (right) of ODI of recorded $V 1$ cells from normally reared (blue) and $4 \mathrm{dMD}(\mathrm{P} 15-\mathrm{P} 19$, red) mice, under the condition of daily brain infusion with the vehicle solution $(\boldsymbol{A}$, Veh) or the solution containing $D Z(B)$, during the pre-CP. The values of $C B I$ are shown in the histogram plots. $p$ values for the comparison between the two cumulative distribution curves in $\boldsymbol{A}$ and $\boldsymbol{B}$ are 0.52 and $<10^{-7}$, respectively (Kolmogorov-Smirnov test). $\boldsymbol{C}$, Summary of the onset latency of evoked contralateral (blue) and ipsilateral (red) PSPs by full-field static gratings in V1 binocular cells from pre-CP mice, with or without chronic DZ infusion. $p$ values are calculated by using the Wilcoxon signed-rank test. $\boldsymbol{D}$, Cumulative distribution of the ipsi-contra latency difference of evoked PSPs in pre-CP mice with different treatments. Significant difference was found between pre- $C P$ and pre-CP-plus-DZ groups (pre-CP+DZ; $p<10^{-8}$, Kolmogorov-Smirnov test).

conditioning for $4 \mathrm{~d}$ affected neither the normal OD distribution (Fig. $8 B$, top) nor the MD-induced OD plasticity (Fig. $8 B, D$ ). Meanwhile, synchronous conditioning also did not affect the developmental emergence of high level of coincidence between binocular inputs in V1 cells during the CP (P25-P26; ipsi-contra PSP latency difference, $5.9 \pm 8.7 \mathrm{~ms}, n=10$ cells in four mice; Fig. $8 E$ ). Thus, the results of asynchronous and synchronous conditioning in Thy1-ChR2 mice provide direct evidence that highly coincident binocular inputs to $\mathrm{V} 1$ are necessary for the induction of OD plasticity during the CP. Although asynchronous and synchronous conditioning differentially influenced the developmental change of binocular input coincidence and the MDinduced OD shift, they did not alter the overall OD distribution of $\mathrm{V} 1$ cell in the binocular zone per se (Fig. $6 B, C$ ). The discrepancy between the changes in individual cell properties and the global structure is reminiscent of a previous finding of unaffected overall map of orientation and direction selectivity in ferret V1 after the similar conditioning (Weliky and Katz, 1997). It might be attributed to the effects of existence of substantial amount of spontaneous correlated binocular activity beyond a limited overall time for the input-pattern conditioning per day.
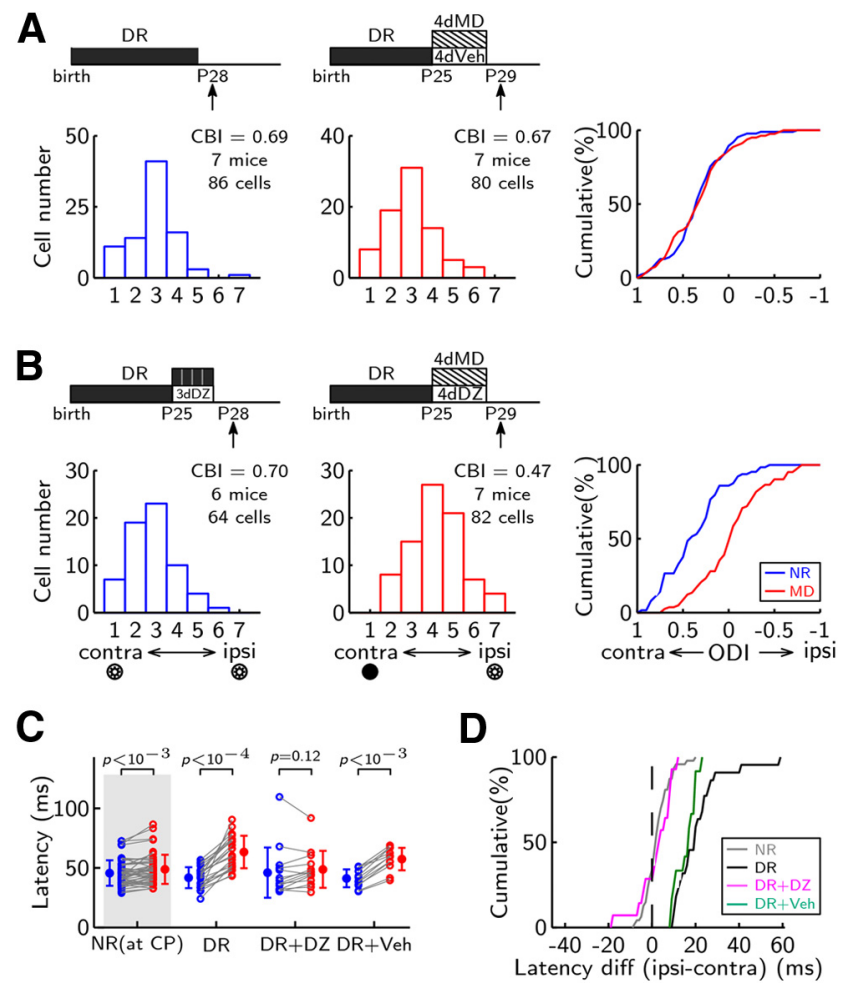

Figure 6. Onset of binocular input coincidence and $C P$ are delayed by dark rearing, but rescued by DZ infusion. $\boldsymbol{A}, \boldsymbol{B}$, Seven-point histograms (left 2 panels) and cumulative distribution (right) of ODI of recorded V1 neurons from DR mice without (blue) and with $4 \mathrm{~d}$ MD (P25-P28, red), under the condition of daily infusion with the vehicle solution ( $\boldsymbol{A}$, Veh) or DZ $(\boldsymbol{B})$. $p$ values for the comparison between the two cumulative distribution curves in $\boldsymbol{A}$ and $\boldsymbol{B}$ are 0.52 and $p<$ $10^{-9}$, respectively (Kolmogorov-Smirnov test). C, Summary of the onset latency of evoked contralateral (blue) and ipsilateral (red) PSPs by full-field static gratings of V1 binocular cells in $D R \sim P 28$ mice, with or without chronic DZ infusion. $p$ values are calculated by Wilcoxon signed-rank test. $\boldsymbol{D}$, Cumulative distribution of the onset latency difference between the contralateral and ipsilateral PSPs in P28 mice with different treatments. Significant difference was found between normalreared (NR) and DR ( $p<10^{-10}$, Kolmogorov-Smirnov test) and between DR and DR-plus-DZ $\left(\mathrm{DR}+\mathrm{DZ} ; p<10^{-6}\right)$, but not between DR and DR-plus-vehicle $(\mathrm{DR}+$ Veh, $p=0.17)$.

\section{Enhancement of binocular visual spiking response during the CP}

Do visually evoked coincident binocular inputs drive binocular cells to fire spikes more efficiently during the CP? To address this question, we performed extracellular single-unit recording in the binocular zone of developing V1 before, during, and after the CP. The rate and reliability of neuronal firing were examined when full-field static gratings were presented to either the contralateral or ipsilateral eye, or to both eyes (Fig. 9A-C). First, we noted that the latency difference between spiking responses evoked by static-grating stimuli presented to the contralateral or ipsilateral eye was significantly smaller during the $\mathrm{CP}(3.7 \pm 8.3 \mathrm{~ms}, n=44$ in 16 mice) than during the pre-CP $(50.0 \pm 9.7 \mathrm{~ms}, n=26$ in 10 mice) and adulthood ( $36.8 \pm 5.4 \mathrm{~ms}, n=30$ cells in 13 mice; Fig. $9 D)$, which is reminiscent of the observations in the case of evoked PSPs (Figs. 1, 4). Second, we found that the amplitude of spiking responses to binocular stimuli was markedly enhanced in binocular cells during the $\mathrm{CP}$, but not during the pre-CP and adulthood, as indicated by the PSTH (Fig. 9E). Similar sublinear binocular integration in young adulthood was also found in a recent study (Zhao et al., 2013). This amplitude increase is consistent with the prediction of a modeling study that found that in the sensory cortex in vivo, synchrony in a very small proportion of inputs results in dramatic increase in the output firing rate (Ros- 
A
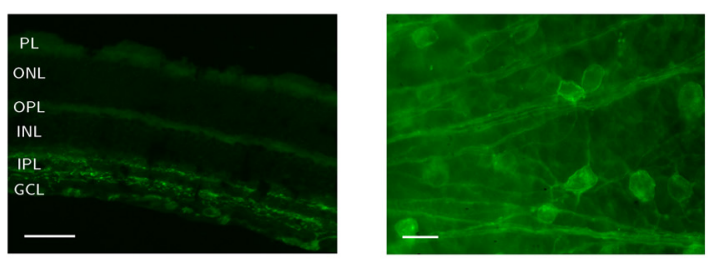

B
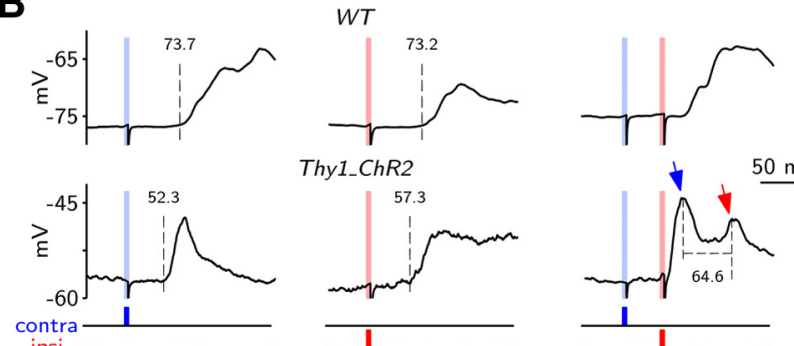

Thy1_ChR2
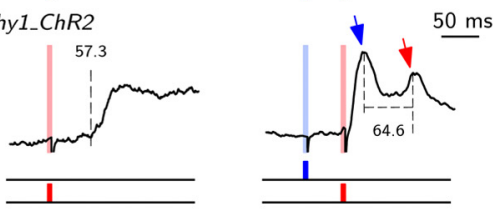

C

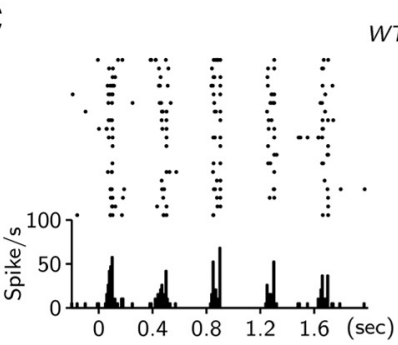

WT
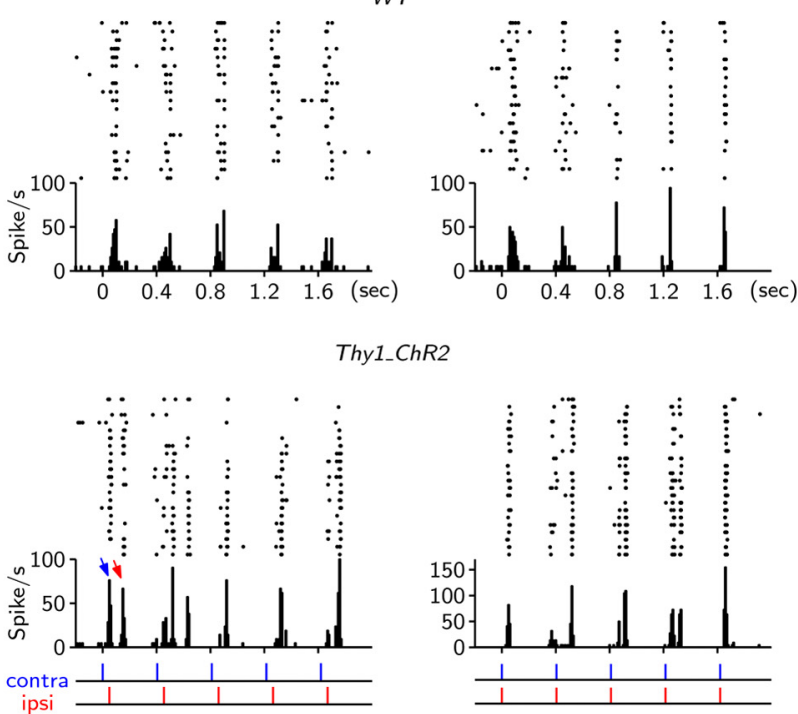

Figure 7. Asynchronous and synchronous activation of the two eye inputs in Thy1-ChR2 mice. A, Fluorescence images of the vertical section (left) and whole-mount (right) of retina of Thy 1-ChR2 transgenic mice, showing that ChR2-EYFP (green) is expressed in ganglion cells and in their dendrites in the inner plexiform layer (IPL). PL, Photoreceptor layer; ONL, outer nuclear layer; $\mathrm{OPL}$, outer plexiform layer; INL, inner nuclear layer; $\mathrm{GCL}$, ganglion cell layer. Scale bar, 25 $\mu \mathrm{m}$. $\boldsymbol{B}$, Traces of subthreshold PSPs evoked by single pulses of blue LED light ( $5 \mathrm{~ms}, \sim 0.4$ $\mathrm{mW} / \mathrm{mm}^{2}$ ) to the contralateral or ipsilateral eye (left 2 traces), respectively, or with $50 \mathrm{~ms}$ intereye interval (right traces) in the WT (top right) or Thy1- ChR2 (bottom right) mice. The bottom diagram indicates the light-stimulation pattern. $C$, Raster and PSTH plots of spike response evoked by trains of blue-light pulses (at $2.5 \mathrm{~Hz}$ ) to the contralateral and ipsilateral eye with 50 (asynchrony, left) and $0 \mathrm{~ms}$ (synchrony, right) interpulse time difference between the eyes in the WT (top row) and Thy1- ChR2 (bottom) mice, respectively. The bottom diagram indicates the light-stimulation pattern.

sant et al., 2011). Third, the reliability of binocular spiking response was markedly increased in binocular cells during the $\mathrm{CP}$, as indicated by the FF for trial-to-trial variability (Fig. 9F). All these CP-specific effects could be attributed to more efficient integration of coincident binocular synaptic activity in binocular cells. Note that these results also suggest that the relatively weaker ipsilateral eye inputs contribute significantly in driving binocular cells to spike specifically during the $\mathrm{CP}$, taking advantage of their increased temporal coincidence with the more dominant contralateral inputs.
A
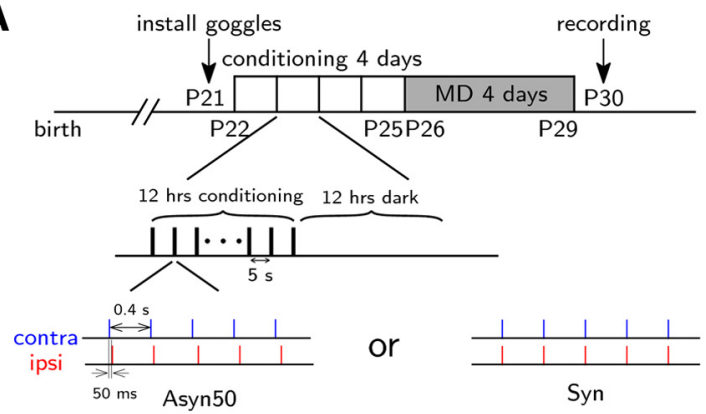

B

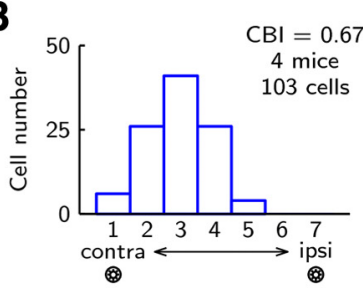

C
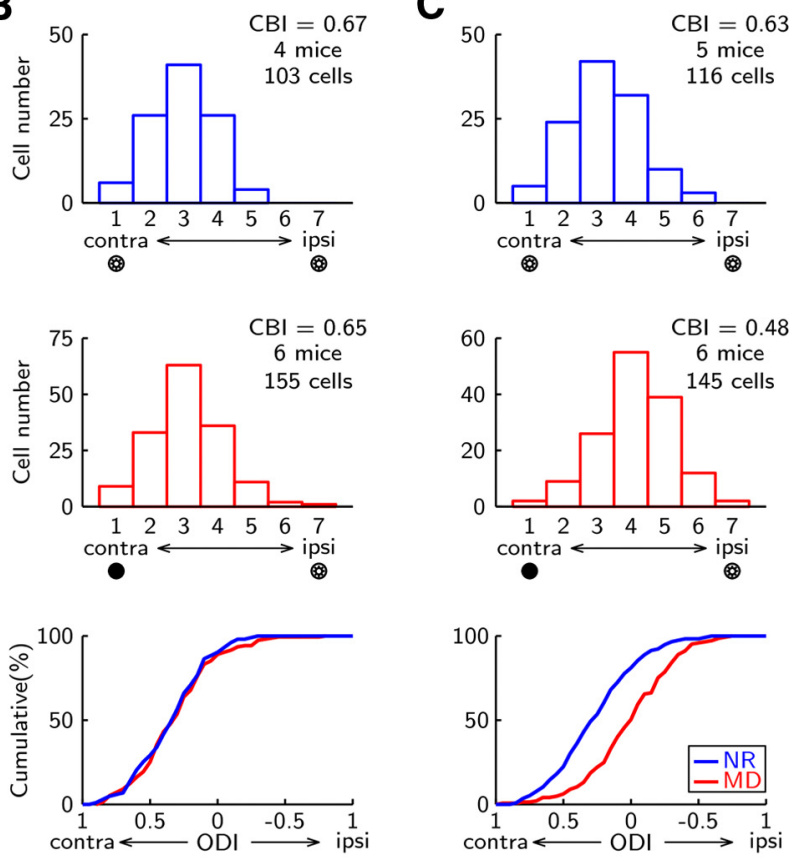

D

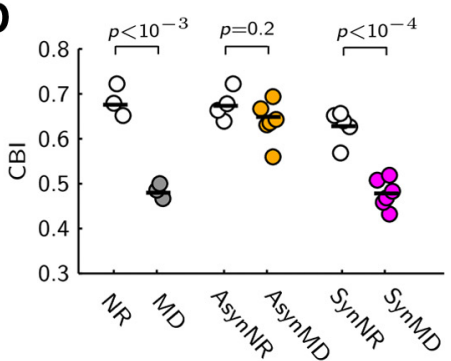

E

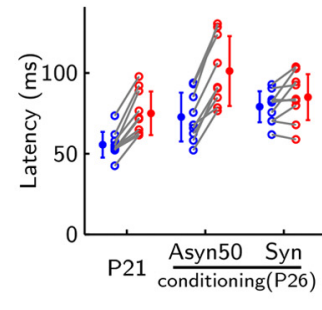

Figure 8. Asynchronous light-conditioning during $C P$ impairs $0 D$ plasticity and binocular input coincidence. $A$, Experimental paradigm. Thy1-ChR2 mice were conditioned with blue LED light stimuli at P22-P25, followed by MD at P26-P29. The mice were conditioned for $12 \mathrm{~h}$ per day in a dark environment. The light stimuli consisted of trains of five light pulses $(5 \mathrm{~ms})$ at 2.5 $\mathrm{Hz}$, with intertrain intervals of $5 \mathrm{~s}$. For the asynchronous conditioning, light pulses to contralateral eye preceded that of the ipsilateral eye by $50 \mathrm{~ms}$ (Asyn50), while in the synchronous conditioning, light pulses were simultaneously applied to the two eyes (Syn). B, C, Seven-point histograms and the cumulative percentage distribution (right) of ODI of recorded V1 neurons from Asyn50 (B) or Syn ( $\boldsymbol{C}$ light-conditioned mice (blue), and from mice with succeeding $4 \mathrm{~d}$ MD (red). $p$ values are 0.95 and $p<10^{-7}$ for $\boldsymbol{B}$ and $\boldsymbol{C}$, respectively (Kolmogorov-Smirnov test). $\boldsymbol{D}$, CBI values of the mice treated with the Asyn50 conditioning (AsynNR) or with succeeding MD (AsynMD), and Syn conditioning (SynNR) or with succeeding MD (SynMD). Each circle represents the CBI value calculated from seven-point histograms of ODI of cells in each mouse, and thick horizontal lines represent the mean CBI for total cells in each group. $p$ values were calculated by the $t$ test. $\boldsymbol{E}$, Summary of the onset latency of contralateral and ipsilateral PSPs evoked by full-field static gratings in Thy 1-ChR2 mice before conditioning (P21) and right after the $4 \mathrm{~d}$ Asyn50 or Syn conditioning (P26). Data connected with a line are from the same cell. Solid circles with error bars: mean \pm SD. 
A
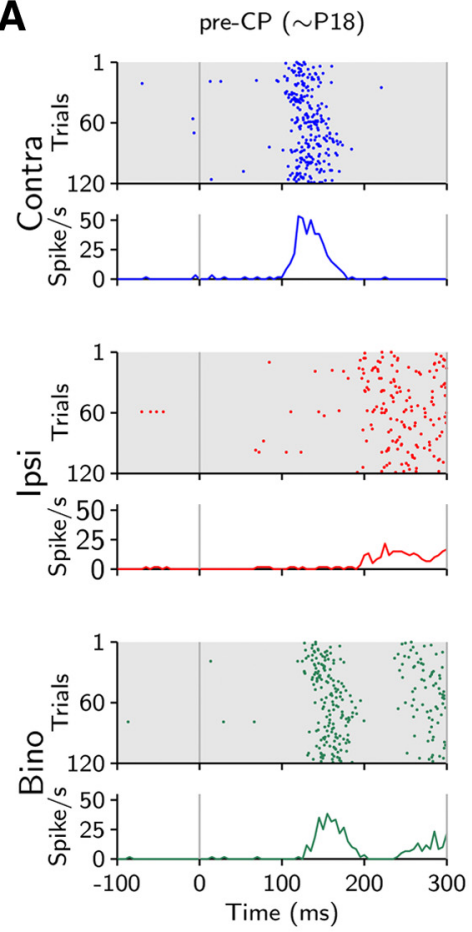

B
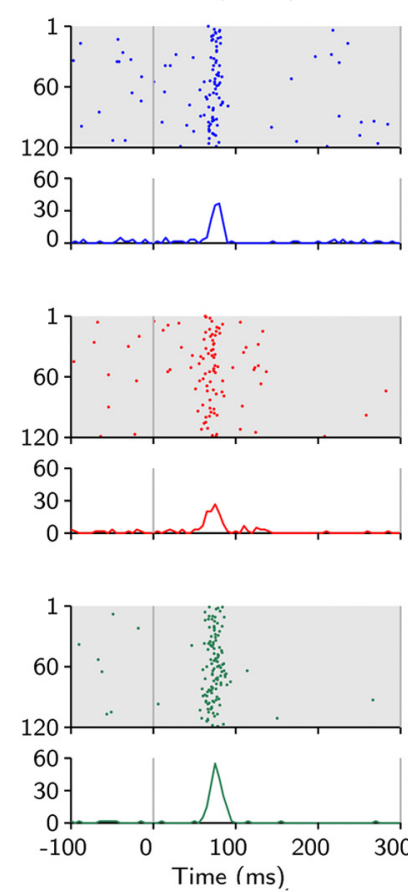

C
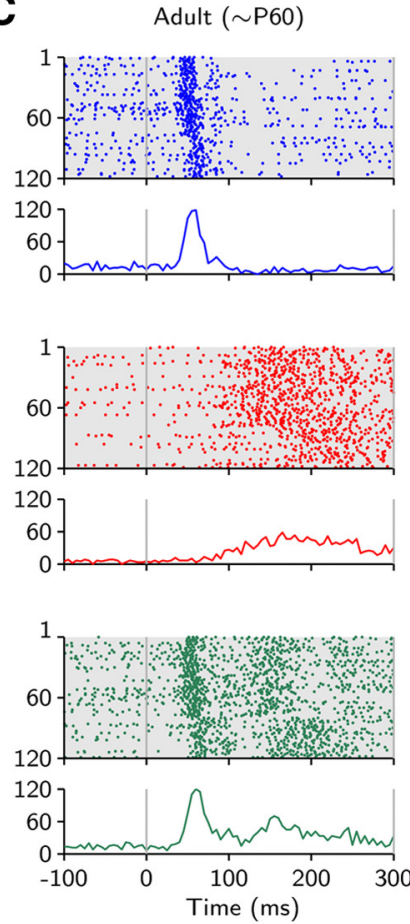
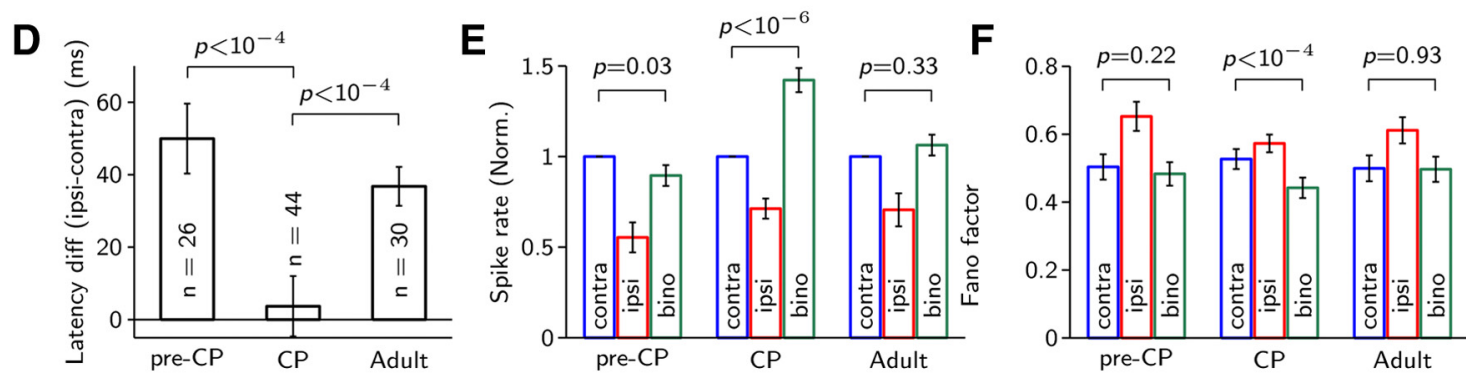

Figure 9. Enhanced visual spiking of binocular cells during (P. $\boldsymbol{A}-\boldsymbol{C}$, Raster plots and PSTHs of visually evoked spikes of example binocular cells recorded extracellularly in the pre-CP $(\boldsymbol{A}), \mathrm{CP}(\boldsymbol{B})$, and adult ( $($ ) mice. Full-field static gratings (of $300 \mathrm{~ms}$ duration, indicated by vertical gray lines) were presented alternately to contralateral or ipsilateral eye, or to both eyes, at the time of $0 \mathrm{~ms}$. Top, Contralateral spikes (blue). Middle, Ipsilateral spikes (red). Bottom, Binocular spikes (green). D, Averaged ipsi-contra latency difference of spiking response in binocular cells recorded in the pre-CP, CP, and adult mice. $p$ values are calculated by Wilcoxon rank-sum test. $n$, Number of recorded cells. $\boldsymbol{E}, \boldsymbol{F}$, Averaged values of the PSTH peak $(\boldsymbol{E})$ and the FF $(\boldsymbol{F})$ of contralateral, ipsilateral, and binocular spiking responses of binocular cells recorded at the three different ages, respectively. Spike rates were normalized to the mean PSTH peak of contralateral response of individual ages. Data from the same cell population as analyzed in $\boldsymbol{D}$. $p$ values are calculated by Wilcoxon signed-rank test. Error bars, SEM.

\section{Modeling of binocular input coincidence-mediated OD plasticity}

Our experimental results have strongly suggested that $\mathrm{CP}$ specific emergence of binocular input coincidence in the developing V1 is required for the induction of MD-induced OD plasticity. To further understand how these coincident binocular inputs can mediate this $\mathrm{CP}$ plasticity, we simulated a feedforward network of cortical neurons with lateral inhibition where synapses adapt to specific visual inputs delivered during pre-CP, CP, and MD periods (see Materials and Methods). Each model neuron received input synapses from two distinct groups of inputs corresponding to contralateral and ipsilateral input pathways. Activity-dependent synaptic modifications occurred following a homeostatic learning rule, namely the $\mathrm{BCM}$ rule (Bienenstock et al., 1982; Intrator and Cooper, 1992) that has been previously applied to the experience-induced OD plasticity (Clothiaux et al., 1991; Cooper and Bear, 2012). In particular, we here used a form of the BCM rule with nonlinear activation function and lateral inhibition (Intrator and Cooper, 1992; Castellani et al., 1999) and implemented synaptic competition via weight vector normalization (Stent, 1973; Miller, 1996). Since our transgenic mice experiment showed that asynchronous or synchronous activation pulses differentially influenced the main effects of MD (Fig. 8), we used a similar input structure in our model simulation. Thus, inputs from both eyes were either synchronous (in the $\mathrm{CP}$ ), or asynchronous (in the pre-CP; Fig. 10A). In more detail, we dissected the visual input stream into discrete temporal time steps (Fig. 10A). In each time step, a visual input pattern was randomly drawn from a pool of possible patterns and embedded into spontaneous rate fluctuations. A particular visual pattern caused a high-rate activation of a selection of input neurons in each time step. Because of asynchronous activation during the pre-CP, high-rate neurons of both input pathways were temporally segregated. In contrast, during the $\mathrm{CP}$, input patterns originating from both eyes became coincident in each time step (as suggested by the experimental results), resulting in an increase of the total amount of inputs to a binocular cortical neuron. Apart from the input structure, all model parameters were set identical in pre- $\mathrm{CP}$ and $\mathrm{CP}$ conditions. In the simulation of $\mathrm{MD}$, input rates from the deprived eye were set to zero, leaving only a some- 

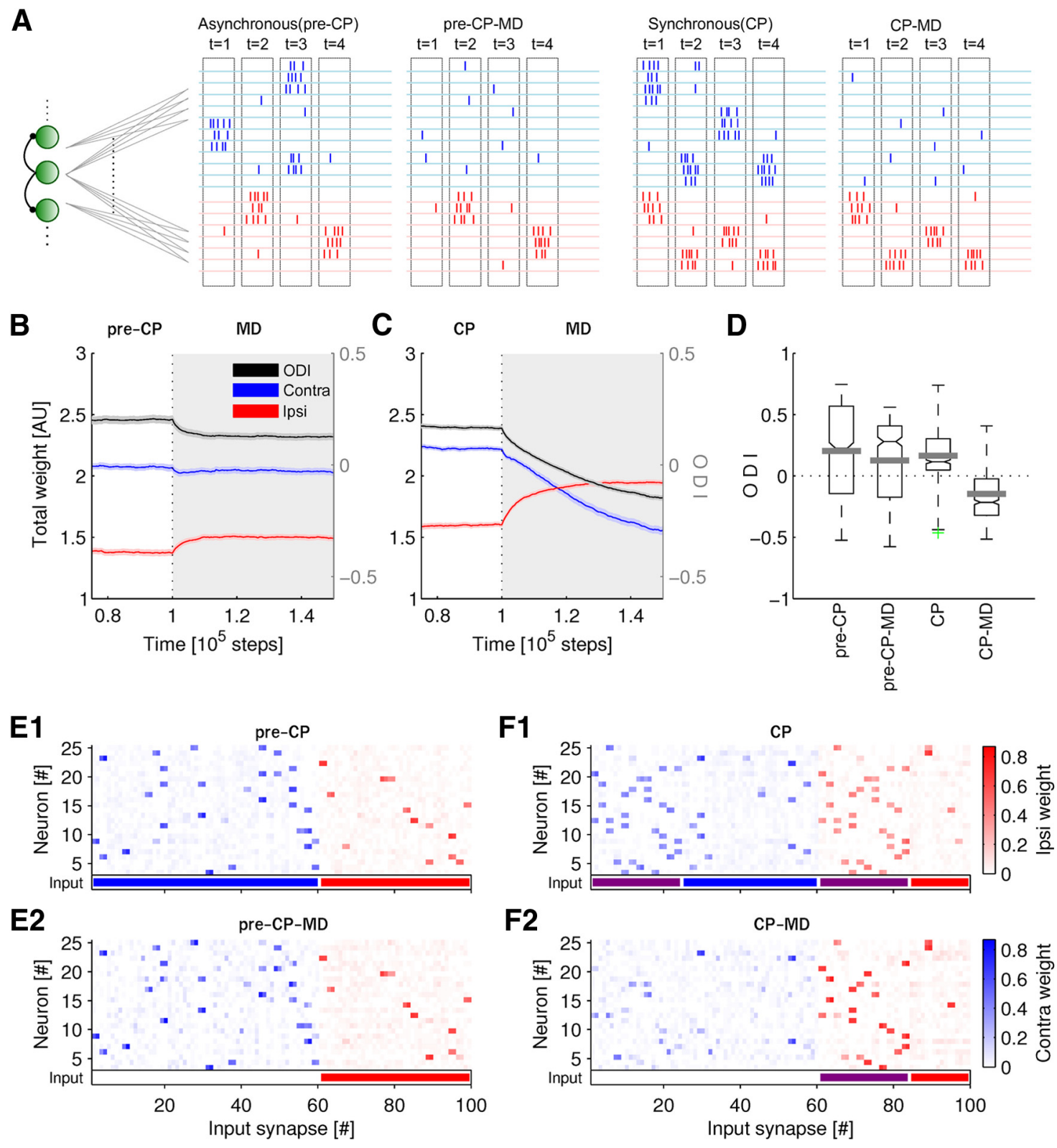

Figure 10. Simulation of binocular input coincidence-mediated OD plasticity. $A$, Schematic illustration of the model and the inputs. Each of 25 cortical neurons received in total 100 convergent feed-forward inputs from the contralateral (60 inputs) and ipsilateral (40 inputs) eyes. Input spike trains illustrate the visual input patterns given at simulation time step $t$ during asynchronous (pre-CP) and synchronous (CP) condition. Visual input is modeled as a high rate of a few selected neurons during a simulation time step t. As illustrated, a single simulation time step in the rate-based model can be seen as the average rate of spiking in a small temporal window (indicated with dashed rectangles). In the simulation, two visual input neurons are highly activated per time step while others show spontaneous activity fluctuations. $\boldsymbol{B}$, In asynchronous condition (pre-CP), MD of the contralateral eye has almost no effect on the total weight of contralateral synapses (blue line) and ipsilateral synapses (red line), and, as a result, the ODI value decreases only slightly. Note that results are averaged over synapses, output neurons, and trials; shaded regions mark the SEM. C, Following $M D$ in the $C P$, the weights of synapses from contralateral eye decrease while the weights of synapse from ipsilateral eye increase, thus the $0 D I$ value decreases dramatically. $D$, $0 D I$ values at time step right before MD onset ( $\boldsymbol{B}, \boldsymbol{C}$, dotted lines) and after MD (last time step of the simulation in $\boldsymbol{B}, \boldsymbol{C}$. 0 DI values are computed for each cortical neuron individually and 25 trials are considered. $E, F$, Learned synaptic weights corresponding to time points as in D for one trial in color code (contralateral, shades of blue; ipsilateral, shades of red). Bars marked "Input" indicate the type of visual input of input neurons during a period (blue, red: temporally segregated contralateral and ipsilateral, respectively; violet: coincident inputs). Note that the weight structure changes strikingly in case of MD in the CP (compare $\boldsymbol{F} \mathbf{1}, \boldsymbol{F}$ ) but stays almost identical after MD during the pre-CP (compare $\boldsymbol{E 1}$, E2).

what larger noise term than during nondeprived periods (see Materials and Methods).

In the model simulations, the initial weights of contralateral and ipsilateral inputs were set to a small random value. However, synaptic weight modification caused the cortical neurons to gradually learn structures of the visual input patterns. Weights of some contralateral and ipsilateral synapses increased, preferring particular input patterns, while weights of other contralateral and ipsilateral synapses remained low. Due to lateral inhibition of cortical neurons as well as synaptic competition, different output neurons commonly learned different aspects of the visual input patterns. Since inputs from contralateral and ipsilateral eyes were temporally segregated during the pre- $\mathrm{CP}$, inputs from both eyes independently contributed to the postsynaptic firing. Note that, because the weight learning integrated visual inputs over multiple time steps, this temporal segregation did not imply that the cortical neurons were purely monocular. After learning, the weights of each pathway reached a steady state (Fig. 10B, blue and 
red curves, left side). A subsequent removal of contralateral inputs during the pre-CP (simulating the MD condition; Fig. 10B, at dotted line) did not significantly affect the total synaptic weights (Fig. 10B; blue and red curves; right side) and the ocular preference of simulated neurons (Fig. 10B, black line). Since the ipsilateral synaptic weights were already optimized for monocular cues during pre-CP, the deprived contralateral pathway did not deliver enough meaningful new signal inputs to trigger a change in the synapses (Fig. $10 \mathrm{E}$, weights of one trial). We plotted the ODI values for each cortical neuron in 25 trials to quantify the effect of the MD on single cells and consequentially found only a small change of the ODI values for MD during the pre-CP (Fig. 10D, gray bars indicate averages). This simulation result corresponds to the experimental finding that short-term MD does not shift the ocular preference of visual cortical cells during the pre-CP (Gordon and Stryker, 1996; Fig. 5A).

In contrast to the pre-CP situation, visual inputs from both eyes arrived at the cortical neuron at the same time step during the CP. Because both pathways now delivered coincident inputs (Fig. $10 \mathrm{~F}$, violet bars), cortical weights reorganize and some synapses adapted to a combination of contralateral and ipsilateral inputs. Thus higher percentage of contralateral and ipsilateral synapses got activated, and neurons now more often contained both strong ipsilateral and strong contralateral weights (Fig. 10F1). Moreover, the homeostatic component of the BCM rule and synaptic competition ensured that strong synapses decreased on average compared with the pre-CP situation, to keep a similar level of firing activity (Fig. 10, compare F1, E1). In consequence, in agreement with the experiments (Sato and Stryker, 2008), the overall weight ratio (as measured by the ODI) remained approximately stable from pre-CP to CP (Fig. 10D). From the model, we observed that a deprivation of contralateral inputs during the $\mathrm{CP}$ (CP-MD) generally caused strong contralateral weights to decay, while strong ipsilateral weights regrew to a similar level during the pre-CP (Fig. 10F2). In particular, contralateral weights emerged from the exposure to the coincident input (Fig. 10F, violet bars) decayed rapidly because of the deprivation-induced mismatch of inputs between ipsilateral and contralateral pathways. Moreover, ipsilateral weights regrew to the pre-CP level (due to homeostasis) and thus additionally forced a reduction of the corresponding strong contralateral weights via synaptic competition. Consequently, the ocular preference of simulated neurons displayed a shift to the nondeprived ipsilateral eye (Fig. $10 C, D)$.

Taken together, the simulation of plasticity during the $\mathrm{CP}$ suggests that coincident binocular inputs during the initial phase of CP may lead to a reorganization of the synaptic weights. This reorganization causes cortical neurons to prefer and rely on coincident input patterns. Monocular deprivation causes the contralateral synapses formed during the coincidence period to decrease because of a mismatch in the inputs and via synaptic competition.

\section{Discussion}

In the present study, we demonstrate that binocular synaptic inputs become highly coincident in cortical binocular cells specifically during the $\mathrm{CP}$, which is required for the MD-induced OD plasticity in the developing mouse V1. Our neural network simulation further presents a potential synaptic mechanism through which the coincidence mediates MD-induced OD shift during the CP. These findings suggest that coincident synaptic inputs from the two eyes emerge as neural substrates for Hebbian synaptic modifications underlying the experience-dependent OD plasticity during the CP.

\section{Correlated neural activity in the developing visual system}

The construction of highly organized neural circuits requires an activity-dependent refinement of early diffuse synaptic connections after their initial formation (Shatz, 1990; Katz and Shatz, 1996). It has been shown that correlated neuronal activities in the retina (Galli and Maffei, 1988; Meister et al., 1991; Wong et al., 1993), dorsal LGN (Weliky and Katz, 1999), and V1 (Chiu and Weliky, 2002) are critical for instructing the formation of eyespecific segregation of afferent eye inputs at different levels of the visual processing pathway (Stryker and Harris, 1986; Cang et al., 2005; Del Rio and Feller, 2006; Huberman et al., 2006). However, there were only few studies that compared the temporal pattern between inputs from the two eyes to the V1. For instance, latencies of evoked single-unit responses to the contralateral eye stimuli were reported to be shorter than that to the ipsilateral eye stimuli in most recorded V1 cells in the adult cat (Minke and Auerbach, 1972). Similarly, shorter latencies in the visually evoked potentials (VEPs) to the contralateral eye stimuli were also found (Minke and Auerbach, 1972). The intereye latency mismatch was also found between dominant and nondominant eyes in monkey (Romero et al., 2007). However, visually evoked spike output and summed population activity VEPs can only indirectly reflect the temporal dynamics of synaptic inputs to the V1. In this study, our in vivo whole-cell recording of binocular synaptic activity (subthreshold PSPs) in single V1 cells has provided direct measurement of temporal patterns of binocular synaptic inputs in the developing V1. Our results suggest that high coincidence of binocular synaptic inputs emerges in V1 binocular cells during the $\mathrm{CP}$, while there is a $\sim 20 \mathrm{~ms}$ discrepancy in the binocular inputs before and after the CP. This temporal discrepancy agrees with a recent finding, revealed by the same whole-cell recording from the $\mathrm{V} 1$ of mice at $\mathrm{P} 30-\mathrm{P} 33$, that onsets of both excitatory and inhibitory currents evoked by contralateral eye stimuli precede that of ipsilateral eye stimuli by $\sim 30 \mathrm{~ms}$ in the binocular cells (Ma et al., 2013).

It is not clear what anatomic and functional basis accounts for differential reduction of latencies of contralateral and ipsilateral inputs to V1 during the development. Several factors might be involved. First, progressive maturation of the myelination of axons along the visual pathway may increase the conduction speed of action potentials over the development (Moore et al., 1976; Beckmann and Albus, 1982; Hildebrand and Waxman, 1984; Tolhurst and Lewis, 1992; Colello et al., 1994). In the retina, relatively longer distance of unmyelinated axon of ipsilaterally projecting RGCs to the optic disc could cause a slightly slower conduction in comparison with contralaterally projecting RGCs (Dräger and Olsen, 1980; Maunsell et al., 1999; May and LutjenDrecoll, 2002). Second, the degree of convergence and coherence of inputs may affect the time it takes to activate the V1 cells. In the monkey retinogeniculate projection, higher input convergence results in shorter response latency (Maunsell et al., 1999). Along the mouse visual pathway from the retina to V1, contralateral projections show higher convergence than ipsilateral ones (Coleman et al., 2009). Functionally, contralateral eye inputs to the V1 are more coherent in the early developmental stage (Crair et al., 1998, 2001; Smith and Trachtenberg, 2007). More coherent inputs could cause a faster ramping of membrane potentials to exceed the noise level, leading to an earlier onset of PSPs detected experimentally. Our modeling stimulation suggests that the rate and coherence of input spikes could dynamically regulate the 
onset latency of PSP responses of postsynaptic cells up to $\sim 20-30$ $\mathrm{ms}$ in the presence of membrane potential noise (data not shown). Thus, the difference in the input convergence and coherence between the two eye pathways can contribute to the onset latency discrepancy.

How developmental changes of binocular inputs contribute to the formation and maintenance of the balanced binocular vision needs to be further examined. In the present study, we demonstrated that, during the $\mathrm{CP}$, emerged coincident synaptic inputs are critical for the binocular contribution to spike generation in postsynaptic V1 binocular cells (Fig. 9). Such spike generation may serve as a cellular mechanism for associative Hebbian synaptic modification that balances and stabilizes binocular synaptic inputs in V1 cells. After the CP, given the ipsicontra onset latency increases to the range of $20-30 \mathrm{~ms}$, this time discrepancy between two eye inputs in the V1 may still be compatible with normal functions of the binocular vision because responses from both eyes still overlap for a substantial period following the onset (Fig. 1, PSP traces).

\section{GABA inhibition regulates correlated binocular activity and CP plasticity}

Maturation of inhibitory GABAergic transmission is one of the key factors that regulate the onset timing of CP (Fagiolini et al., 2004; Hensch, 2005; Espinosa and Stryker, 2012). In addition to the known effect of inducing the CP onset, we showed that enhancing GABAergic transmission by chronic brain infusion of $\mathrm{DZ}$ also regulates the emergence of binocular input coincidence (Figs. 5, 6). Interestingly, the DZ effect on the latency of afferent eye inputs in V1 binocular cells was different between the two eyes' input pathways, in which DZ treatment caused a larger reduction of the response latency of ipsilateral inputs in mice of pre-CP or when dark-reared (Figs. $5 C, 6 C$ ). However, how the enhanced inhibition differentially regulates response latency is unclear. One possible mechanism is that enhancing GABA transmission could enforce the temporal precision of spike output (Pouille and Scanziani, 2001; Mittmann et al., 2005) and consequently strengthen the coherence of convergent presynaptic cell inputs (Kuhlman et al., 2010; H. P. Wang et al., 2010), which may decrease the response latency along the visual pathway. The differential effects of enhancing inhibition might be attributed to different baseline levels of the coherence of input to the V1 between the two pathways during the early development stage (Crair et al., 1998, 2001; Smith and Trachtenberg, 2007).

Different hypotheses have been proposed to understand how the maturation of inhibitory circuits induces the CP of the developing visual circuit (Espinosa and Stryker, 2012; Toyoizumi et al., 2013). Among them, a prevailing hypothesis is that inhibition controls the CP plasticity by regulating the correlation patterns between binocular inputs in V1 (Feldman, 2000; Hensch, 2005). In the present study, our findings provide strong evidence supporting the consecutive events in the hypothesis: increased inhibition leads to correlated binocular activity, which in turn leads to induction of CP plasticity.

\section{Hypothetical mechanism for binocular input coincidence- mediated OD plasticity}

Through modeling simulation, we have suggested a potential mechanism for how the coincident inputs might cause the induction of MD-induced OD plasticity specifically during the CP. Our main hypothesis is that, due to asynchronous inputs during pre$\mathrm{CP}$, input weights from the contralateral and ipsilateral pathways are first independently adjusted and optimized individually for each pathway. After synaptic weight modifications, cortical neurons thus respond well to mono-ocular cues and interdependence of the input pathways on the response is low. Deprivation of visual signals in one pathway does not affect the other pathway weight structure. On the other hand, coincident inputs from the two eyes during $\mathrm{CP}$ subtly change the synaptic weights in both pathways through Hebbian learning: an interdependent weight structure emerges due to the coincident arrival of visual inputs from the two eyes. After exposure to coincident inputs during the initial CP, monocular deprivation has a striking effect: the interdependent weight structure collapses due to the lack of coincident input in the deprived eye. The reasons are twofold. First, mismatch of the expected input in the deprived pathway causes these weights to decay in face of the background noise. Second, the nondeprived weights slightly increase due to the homeostatic readjustment to the reduced drive of the single pathway input. Competition between synapses exerts further downward pressure on the weights of the deprived pathway. Taken together, the average weight of the deprived contralateral pathway decreases for $\mathrm{MD}$ after a coincident period (in the $\mathrm{CP}$ ) but not in the pre-CP. These differential changes of synaptic weights in deprived and nondeprived eye inputs, described in our simulation, are largely consistent with the experimental findings (Frenkel and Bear, 2004; Kaneko et al., 2008). Note that in our model we do not assume that parameters change from pre-CP to CP; all differential effects are solely based on the changes in the input structure. However, this change in input structure might be in turn a consequence of developments in the cortex (for instance, maturing inhibition, as discussed above). These developmental changes are thus only implicitly included in our simulation. Overall, our neural network simulation suggests a potential mechanism underlying the binocular input coincidence-mediated reorganization of synaptic weights in the developing V1 cortical circuits.

\section{References}

Adesnik H, Bruns W, Taniguchi H, Huang ZJ, Scanziani M (2012) A neural circuit for spatial summation in visual cortex. Nature 490:226-231. CrossRef Medline

Anderson J, Lampl I, Reichova I, Carandini M, Ferster D (2000) Stimulus dependence of two-state fluctuations of membrane potential in cat visual cortex. Nat Neurosci 3:617-621. CrossRef Medline

Arenkiel BR, Peca J, Davison IG, Feliciano C, Deisseroth K, Augustine GJ, Ehlers MD, Feng G (2007) In vivo light-induced activation of neural circuitry in transgenic mice expressing channelrhodopsin-2. Neuron 54: 205-218. CrossRef Medline

Bair W, Cavanaugh JR, Movshon JA (2003) Time course and time-distance relationships for surround suppression in macaque V1 neurons. J Neurosci 23:7690-7701. Medline

Beckmann R, Albus K (1982) The geniculocortical system in the early postnatal kitten: an electrophysiological investigation. Exp Brain Res 47:4956. Medline

Bienenstock EL, Cooper LN, Munro PW (1982) Theory for the development of neuron selectivity: orientation specificity and binocular interaction in visual cortex. J Neurosci 2:32-48. Medline

Cang J, Rentería RC, Kaneko M, Liu X, Copenhagen DR, Stryker MP (2005) Development of precise maps in visual cortex requires patterned spontaneous activity in the retina. Neuron 48:797-809. CrossRef Medline

Carandini M, Heeger DJ, Movshon JA (1997) Linearity and normalization in simple cells of the macaque primary visual cortex. J Neurosci 17:86218644. Medline

Castellani GC, Intrator N, Shouval H, Cooper LN (1999) Solutions of the BCM learning rule in a network of lateral interacting nonlinear neurons. Network 10:111-121. Medline

Chiu C, Weliky M (2002) Relationship of correlated spontaneous activity to functional ocular dominance columns in the developing visual cortex. Neuron 35:1123-1134. CrossRef Medline

Clothiaux EE, Bear MF, Cooper LN (1991) Synaptic plasticity in visual cor- 
tex: comparison of theory with experiment. J Neurophysiol 66:17851804. Medline

Colello RJ, Pott U, Schwab ME (1994) The role of oligodendrocytes and myelin on axon maturation in the developing rat retinofugal pathway. J Neurosci 14:2594-2605. Medline

Coleman JE, Law K, Bear MF (2009) Anatomical origins of ocular dominance in mouse primary visual cortex. Neuroscience 161:561-571. CrossRef Medline

Cooper LN, Bear MF (2012) The BCM theory of synapse modification at 30: interaction of theory with experiment. Nat Rev Neurosci 13:798-810. CrossRef Medline

Crair MC, Gillespie DC, Stryker MP (1998) The role of visual experience in the development of columns in cat visual cortex. Science 279:566-570. CrossRef Medline

Crair MC, Horton JC, Antonini A, Stryker MP (2001) Emergence of ocular dominance columns in cat visual cortex by 2 weeks of age. J Comp Neurol 430:235-249. CrossRef Medline

DeAngelis GC, Ohzawa I, Freeman RD (1993) Spatiotemporal organization of simple-cell receptive fields in the cat's striate cortex. II. Linearity of temporal and spatial summation. J Neurophysiol 69:1118-1135. Medline

Del Rio T, Feller MB (2006) Early retinal activity and visual circuit development. Neuron 52:221-222. CrossRef Medline

Douglas RJ, Martin KA (2004) Neuronal circuits of the neocortex. Annu Rev Neurosci 27:419-451. CrossRef Medline

Dräger UC (1975) Receptive-fields of single cells and topography in mouse visual cortex. J Comp Neurol 160:269-290. CrossRef Medline

Dräger UC (1978) Observations on monocular deprivation in mice. J Neurophysiol 41:28-42. Medline

Dräger UC, Olsen JF (1980) Origins of crossed and uncrossed retinal projections in pigmented and albino mice. J Comp Neurol 191:383-412. CrossRef Medline

Espinosa JS, Stryker MP (2012) Development and plasticity of the primary visual cortex. Neuron 75:230-249. CrossRef Medline

Fagiolini M, Pizzorusso T, Berardi N, Domenici L, Maffei L (1994) Functional postnatal development of the rat primary visual cortex and the role of visual experience: dark rearing and monocular deprivation. Vision Res 34:709-720. CrossRef Medline

Fagiolini M, Hensch TK (2000) Inhibitory threshold for critical-period activation in primary visual cortex. Nature 404:183-186. CrossRef Medline

Fagiolini M, Fritschy JM, Löw K, Möhler H, Rudolph U, Hensch TK (2004) Specific $\mathrm{GABA}_{\mathrm{A}}$ circuits for visual cortical plasticity. Science 303:16811683. CrossRef Medline

Feldman DE (2000) Inhibition and plasticity. Nat Neurosci 3:303-304. CrossRef Medline

Frenkel MY, Bear MF (2004) How monocular deprivation shifts ocular dominance in visual cortex of young mice. Neuron 44:917-923. CrossRef Medline

Galli L, Maffei L (1988) Spontaneous impulse activity of rat retinal ganglion cells in prenatal life. Science 242:90-91. CrossRef Medline

Gilbert CD, Wiesel TN (1979) Morphology and intracortical projections of functionally characterised neurones in the cat visual cortex. Nature 280: 120-125. CrossRef Medline

Gordon JA, Stryker MP (1996) Experience-dependent plasticity of binocular responses in the primary visual cortex of the mouse. J Neurosci 16: 3274-3286. Medline

Harris KD, Hirase H, Leinekugel X, Henze DA, Buzsáki G (2001) Temporal interaction between single spikes and complex spike bursts in hippocampal pyramidal cells. Neuron 32:141-149. CrossRef Medline

Hensch TK (2005) Critical period plasticity in local cortical circuits. Nat Rev Neurosci 6:877-888. CrossRef Medline

Hensch TK, Fagiolini M, Mataga N, Stryker MP, Baekkeskov S, Kash SF (1998) Local GABA circuit control of experience-dependent plasticity in developing visual cortex. Science 282:1504-1508. CrossRef Medline

Hildebrand C, Waxman SG (1984) Postnatal differentiation of rat optic nerve fibers: electron microscopic observations on the development of nodes of Ranvier and axoglial relations. J Comp Neurol 224:25-37. CrossRef Medline

Hubel DH, Wiesel TN (1965) Binocular interaction in striate cortex of kittens reared with artificial squint. J Neurophysiol 28:1041-1059. Medline

Hubel DH, Wiesel TN (1968) Receptive fields and functional architecture of monkey striate cortex. J Physiol 195:215-243. Medline

Hubel DH, Wiesel TN (1970) The period of susceptibility to the physiolog- ical effects of unilateral eye closure in kittens. J Physiol 206:419-436. Medline

Hubel DH, Wiesel TN, LeVay S (1977) Plasticity of ocular dominance columns in monkey striate cortex. Philos Trans R Soc Lond B Biol Sci 278: 377-409. CrossRef Medline

Huberman AD, Speer CM, Chapman B (2006) Spontaneous retinal activity mediates development of ocular dominance columns and binocular receptive fields in V1. Neuron 52:247-254. CrossRef Medline

Intrator N, Cooper LN (1992) Objective function formulation of the BCM theory of visual cortical plasticity: statistical connections, stability conditions. Neural Netw 5:3-17. CrossRef

Issa NP, Trachtenberg JT, Chapman B, Zahs KR, Stryker MP (1999) The critical period for ocular dominance plasticity in the Ferret's visual cortex. J Neurosci 19:6965-6978. Medline

Iwai Y, Fagiolini M, Obata K, Hensch TK (2003) Rapid critical period induction by tonic inhibition in visual cortex. J Neurosci 23:6695-6702. Medline

Kaneko M, Stellwagen D, Malenka RC, Stryker MP (2008) Tumor necrosis factor-alpha mediates one component of competitive, experiencedependent plasticity in developing visual cortex. Neuron 58:673-680. CrossRef Medline

Kara P, Reinagel P, Reid RC (2000) Low response variability in simultaneously recorded retinal, thalamic, and cortical neurons. Neuron 27:635646. CrossRef Medline

Katz LC, Shatz CJ (1996) Synaptic activity and the construction of cortical circuits. Science 274:1133-1138. CrossRef Medline

Kennedy H, Orban GA (1983) Response properties of visual cortical neurons in cats reared in stroboscopic illumination. J Neurophysiol 49:686704. Medline

Kuhlman SJ, Lu J, Lazarus MS, Huang ZJ (2010) Maturation of GABAergic inhibition promotes strengthening of temporally coherent inputs among convergent pathways. PLoS Comput Biol 6:e1000797. CrossRef Medline

LeVay S, Wiesel TN, Hubel DH (1980) The development of ocular dominance columns in normal and visually deprived monkeys. J Comp Neurol 191:1-51. CrossRef Medline

Li YT, Ma WP, Li LY, Ibrahim LA, Wang SZ, Tao HW (2012) Broadening of inhibitory tuning underlies contrast-dependent sharpening of orientation selectivity in mouse visual cortex. J Neurosci 32:16466-16477. CrossRef Medline

Ma WP, Li YT, Tao HW (2013) Downregulation of cortical inhibition mediates ocular dominance plasticity during the critical period. J Neurosci 33:11276-11280. CrossRef Medline

Maffei L, Bisti S (1976) Binocular interaction in strabismic kittens deprived of vision. Science 191:579-580. CrossRef Medline

Maffei L, Berardi N, Domenici L, Parisi V, Pizzorusso T (1992) Nerve growth factor (NGF) prevents the shift in ocular dominance distribution of visual cortical neurons in monocularly deprived rat. J Neurosci 12: 4651-4662. Medline

Maunsell JH, Gibson JR (1992) Visual response latencies in striate cortex of the macaque monkey. J Neurophysiol 68:1332-1344. Medline

Maunsell JH, Ghose GM, Assad JA, McAdams CJ, Boudreau CE, Noerager BD (1999) Visual response latencies of magnocellular and parvocellular LGN neurons in macaque monkeys. Vis Neurosci 16:1-14. Medline

May CA, Lütjen-Drecoll E (2002) Morphology of the murine optic nerve. Invest Ophthalmol Vis Sci 43:2206-2212. Medline

Mazer JA, Vinje WE, McDermott J, Schiller PH, Gallant JL (2002) Spatial frequency and orientation tuning dynamics in area V1. Proc Natl Acad Sci U S A 99:1645-1650. CrossRef Medline

Meister M, Wong RO, Baylor DA, Shatz CJ (1991) Synchronous bursts of action potentials in ganglion cells of the developing mammalian retina. Science 252:939-943. CrossRef Medline

Meister ML, Hennig JA, Huk AC (2013) Signal multiplexing and singleneuron computations in lateral intraparietal area during decisionmaking. J Neurosci 33:2254-2267. CrossRef Medline

Miller KD (1996) Synaptic economics: competition and cooperation in synaptic plasticity. Neuron 17:371-374. CrossRef Medline

Miller KD, Keller JB, Stryker MP (1989) Ocular dominance column development: analysis and simulation. Science 245:605-615. CrossRef Medline

Minke B, Auerbach E (1972) Latencies and correlation in single units and visual evoked potentials in the cat striate cortex following monocular and binocular stimulations. Exp Brain Res 14:409-422. Medline 
Mittmann W, Koch U, Häusser M (2005) Feed-forward inhibition shapes the spike output of cerebellar Purkinje cells. J Physiol 563:369-378. CrossRef Medline

Moore CL, Kalil R, Richards W (1976) Development of myelination in optic tract of the cat. J Comp Neurol 165:125-136. CrossRef Medline

Mower GD (1991) The effect of dark rearing on the time course of the critical period in cat visual cortex. Brain Res Dev Brain Res 58:151-158. CrossRef Medline

Ohzawa I, Freeman RD (1988) Binocularly deprived cats: binocular tests of cortical cells show regular patterns of interaction. J Neurosci 8:25072516. Medline

Oram MW (2010) Contrast induced changes in response latency depend on stimulus specificity. J Physiol Paris 104:167-175. CrossRef Medline

Pouille F, Scanziani M (2001) Enforcement of temporal fidelity in pyramidal cells by somatic feed-forward inhibition. Science 293:1159-1163. CrossRef Medline

Romero MC, Castro AF, Bermudez MA, Perez R, Gonzalez F (2007) Eye dominance and response latency in area V1 of the monkey. Vis Neurosci 24:757-761. Medline

Rossant C, Leijon S, Magnusson AK, Brette R (2011) Sensitivity of noisy neurons to coincident inputs. J Neurosci 31:17193-17206. CrossRef Medline

Sato M, Stryker MP (2008) Distinctive features of adult ocular dominance plasticity. J Neurosci 28:10278-10286. CrossRef Medline

Shadlen MN, Newsome WT (1998) The variable discharge of cortical neurons: implications for connectivity, computation, and information coding. J Neurosci 18:3870-3896. Medline

Shatz CJ (1990) Impulse activity and the patterning of connections during CNS development. Neuron 5:745-756. CrossRef Medline

Shatz CJ, Stryker MP (1978) Ocular dominance in layer IV of the cat's visual cortex and the effects of monocular deprivation. J Physiol 281:267-283. Medline

Smith MA (2006) Surround suppression in the early visual system. J Neurosci 26:3624-3625. CrossRef Medline

Smith SL, Trachtenberg JT (2007) Experience-dependent binocular competition in the visual cortex begins at eye opening. Nat Neurosci 10:370375. CrossRef Medline

Smith EL 3rd, Bennett MJ, Harwerth RS, Crawford ML (1979) Binocularity in kittens reared with optically induced squint. Science 204:875-877. CrossRef Medline

Song S, Abbott LF (2001) Cortical development and remapping through spike timing-dependent plasticity. Neuron 32:339-350. CrossRef Medline

Song S, Miller KD, Abbott LF (2000) Competitive Hebbian learning through spike-timing-dependent synaptic plasticity. Nat Neurosci 3:919926. CrossRef Medline

Stent GS (1973) A physiological mechanism for Hebb's postulate of learning. Proc Natl Acad Sci U S A 70:997-1001. CrossRef Medline

Stryker MP, Harris WA (1986) Binocular impulse blockade prevents the formation of ocular dominance columns in cat visual cortex. J Neurosci 6:2117-2133. Medline

Thyagarajan S, van Wyk M, Lehmann K, Löwel S, Feng G, Wässle H (2010) Visual function in mice with photoreceptor degeneration and transgenic expression of channelrhodopsin 2 in ganglion cells. J Neurosci 30:87458758. CrossRef Medline

Tolhurst DJ, Lewis PR (1992) Effect of myelination on the conduction velocity of optic nerve fibres. Ophthalmic Physiol Opt 12:241-243. Medline

Toyoizumi T, Miyamoto H, Yazaki-Sugiyama Y, Atapour N, Hensch TK, Miller KD (2013) A theory of the transition to critical period plasticity: inhibition selectively suppresses spontaneous activity. Neuron 80:51-63. CrossRef Medline

Tucker TR, Fitzpatrick D (2006) Luminance-evoked inhibition in primary visual cortex: a transient veto of simultaneous and ongoing response. J Neurosci 26:13537-13547. CrossRef Medline

Van den Bergh G, Zhang B, Arckens L, Chino YM (2010) Receptive-field properties of V1 and V2 neurons in mice and macaque monkeys. J Comp Neurol 518:2051-2070. CrossRef Medline

Wang BS, Sarnaik R, Cang J (2010) Critical period plasticity matches binocular orientation preference in the visual cortex. Neuron 65:246-256. CrossRef Medline

Wang HP, Spencer D, Fellous JM, Sejnowski TJ (2010) Synchrony of thalamocortical inputs maximizes cortical reliability. Science 328:106109. CrossRef Medline

Weliky M, Katz LC (1997) Disruption of orientation tuning in visual cortex by artificially correlated neuronal activity. Nature 386:680-685. CrossRef Medline

Weliky M, Katz LC (1999) Correlational structure of spontaneous neuronal activity in the developing lateral geniculate nucleus in vivo. Science 285 : 599-604. CrossRef Medline

Wiesel TN, Hubel DH (1963) Single-cell responses in striate cortex of kittens deprived of vision in one eye. J Neurophysiol 26:1003-1017. Medline

Wiesel TN, Hubel DH (1965) Comparison of the effects of unilateral and bilateral eye closure on cortical unit responses in kittens. J Neurophysiol 28:1029-1040. Medline

Wong RO, Meister M, Shatz CJ (1993) Transient period of correlated bursting activity during development of the mammalian retina. Neuron 11: 923-938. CrossRef Medline

Ye CQ, Poo MM, Dan Y, Zhang XH (2010) Synaptic mechanisms of direction selectivity in primary auditory cortex. J Neurosci 30:1861-1868. CrossRef Medline

Zhang B, Smith EL 3rd, Chino YM (2008) Postnatal development of onset transient responses in macaque V1 and V2 neurons. J Neurophysiol 100: 1476-1487. CrossRef Medline

Zhang J, Ackman JB, Xu HP, Crair MC (2012) Visual map development depends on the temporal pattern of binocular activity in mice. Nat Neurosci 15:298-307. CrossRef Medline

Zhao X, Liu M, Cang J (2013) Sublinear binocular integration preserves orientation selectivity in mouse visual cortex. Nat Commun 4:20882307. CrossRef Medline 